\section{Rapid Quantitation of Gene Therapy Specific CFTR Expression Using the Amplification Refractory Mutation System}

BioTechniques 27:122-127 (July 1999)

\begin{abstract}
Gene therapy offers the potential of correcting genetic disorders such as cystic fibrosis $(C F)$. By complementing the nonfunctional endogenous cystic fibrosis transmembrane conductance regulator (CFTR) gene with a functional transgene, we anticipate it may alleviate the disease phenotype. All approaches to CF gene therapy rely upon sensitive assays to monitor delivery, expression and maintenance of CFTR vectors. Here, we describe the adaptation of the amplification refractory mutation system (ARMS) to discriminate between different forms of CFTR. A LightCycler ${ }^{\mathrm{TM}}$ PCR machine allows realtime continuous fluorescence monitoring of rapid-cycle PCR. We show quantitation of and discrimination between expression of endogenous (wild-type or mutant) CFTR and the introduced transgene.
\end{abstract}

\section{INTRODUCTION}

Cystic fibrosis (CF) gene therapy is being pioneered in the lung because in addition to being the organ most severely affected by $\mathrm{CF}$, it is directly accessible to aerosolized reagents. While showing promise, current vectors only show partial and transient correction of the CF phenotype (see Reference 1 and references therein). Therefore studies are aimed at improving the existing gene therapy protocols and designing new ones to overcome the physical and biological blocks to gene therapy (for review see Reference 3 ).

To facilitate bacterial cloning of cystic fibrosis transmembrane conductance regulator (CFTR), Gregory et al. (5) introduced a neutral mutation into the CFTR gene $(936 \mathrm{~T} \rightarrow \mathrm{C}$ ) that silences

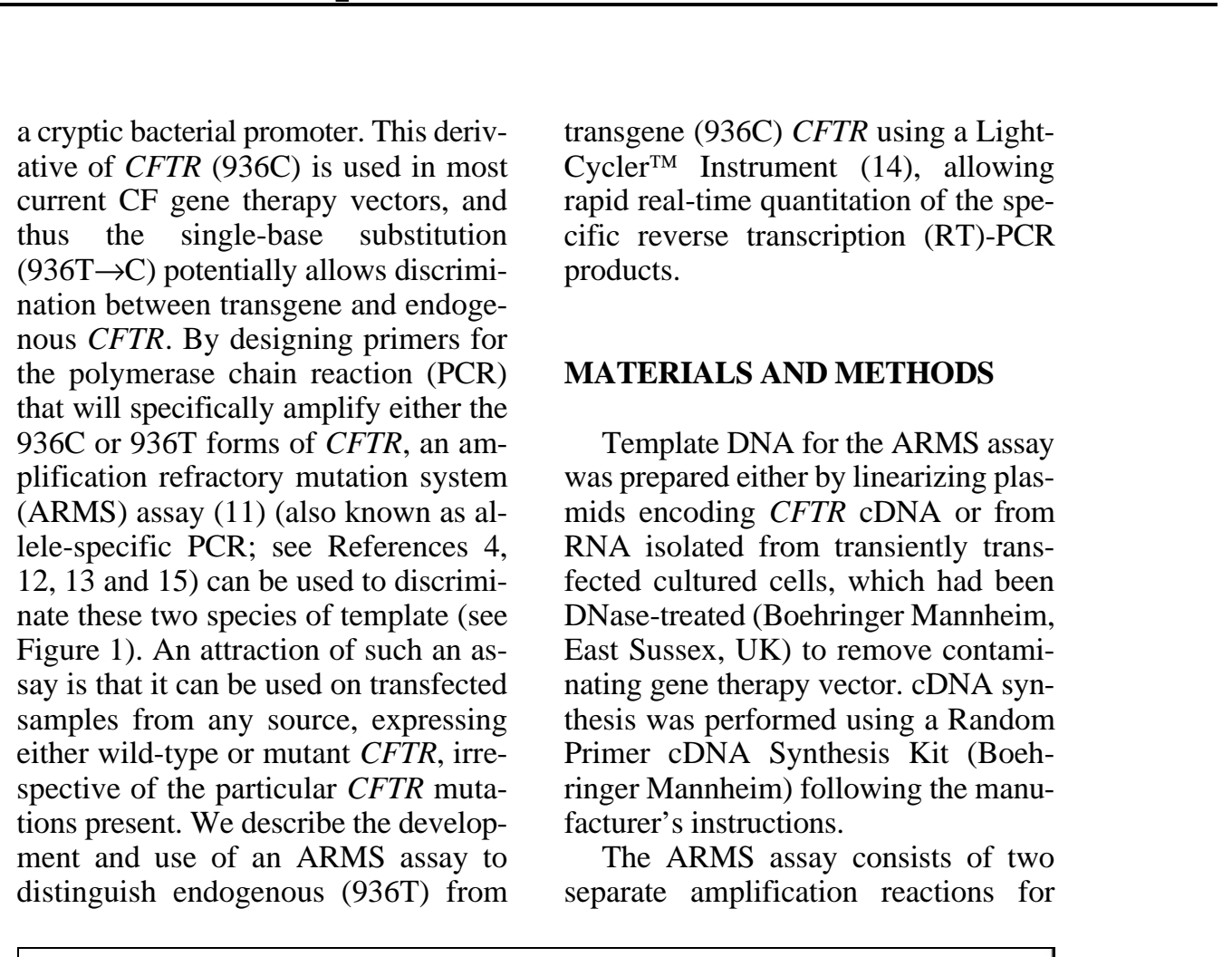

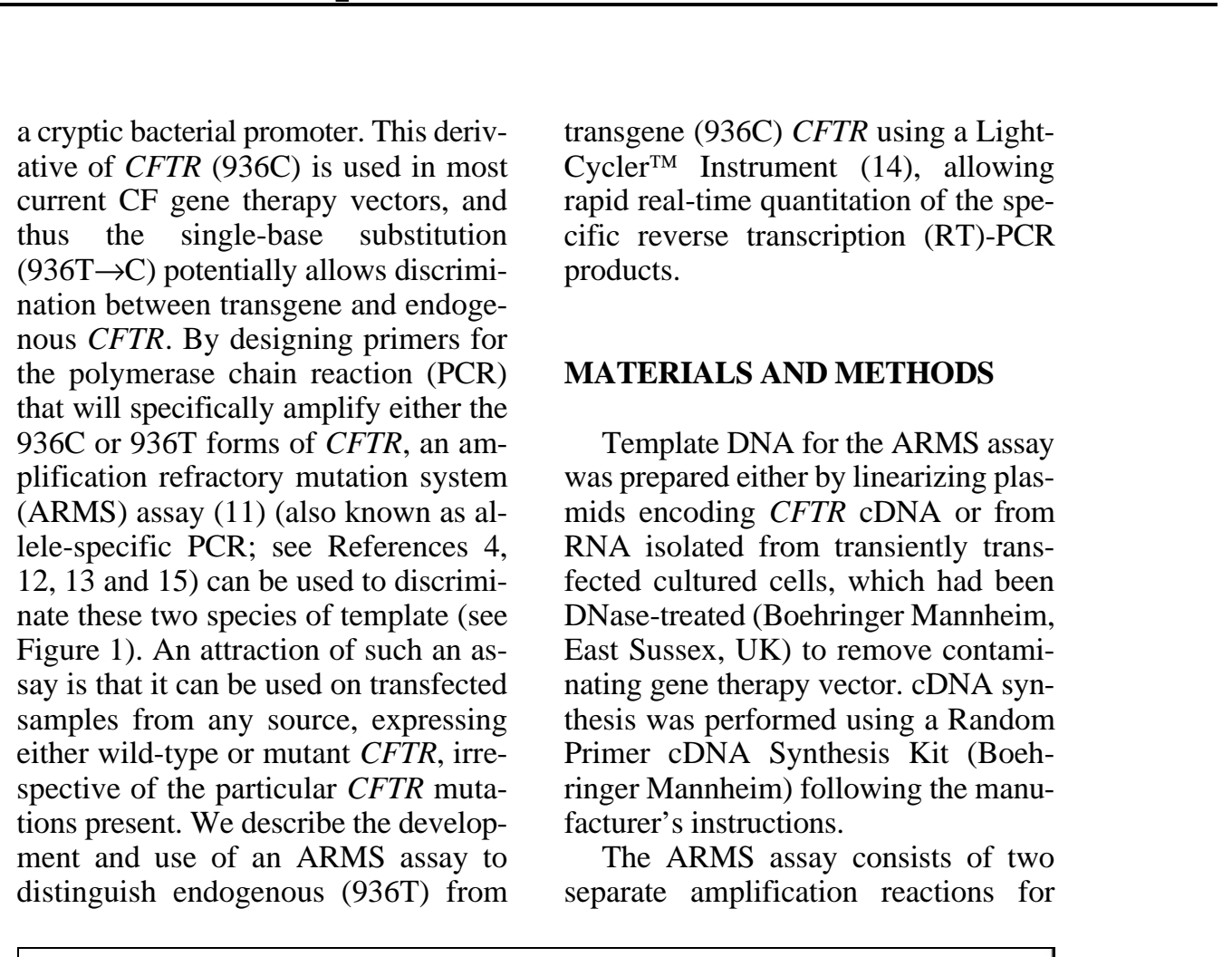

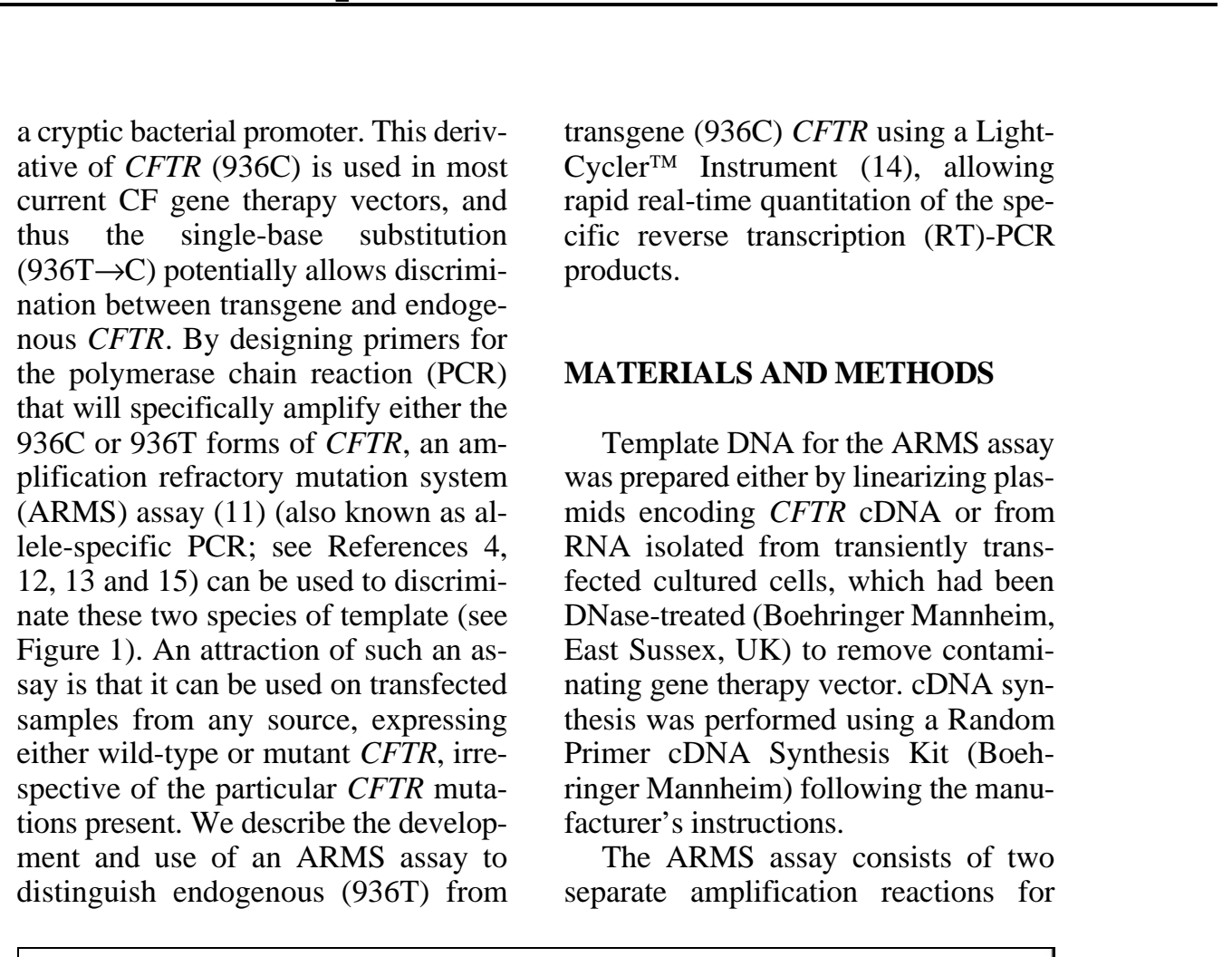

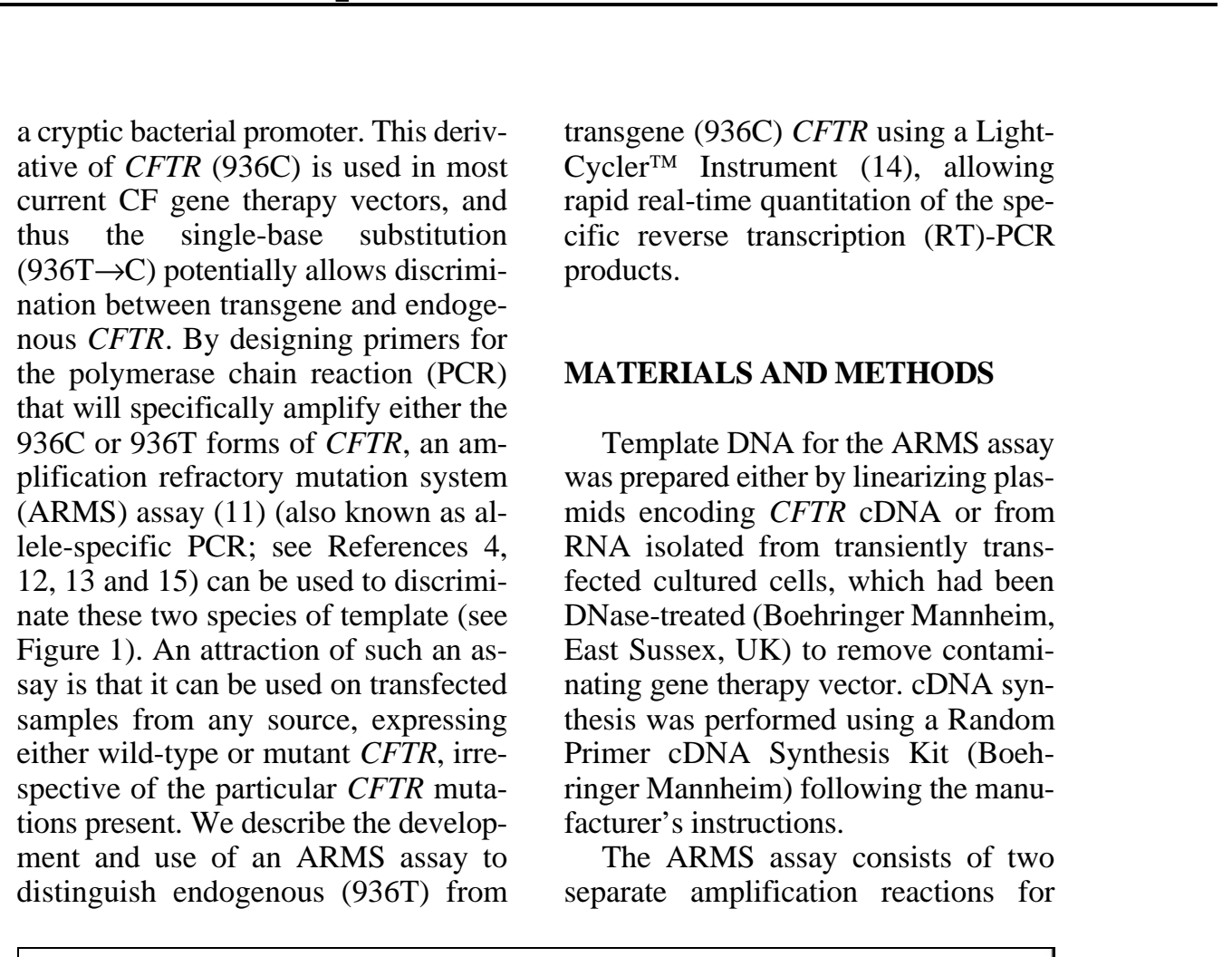

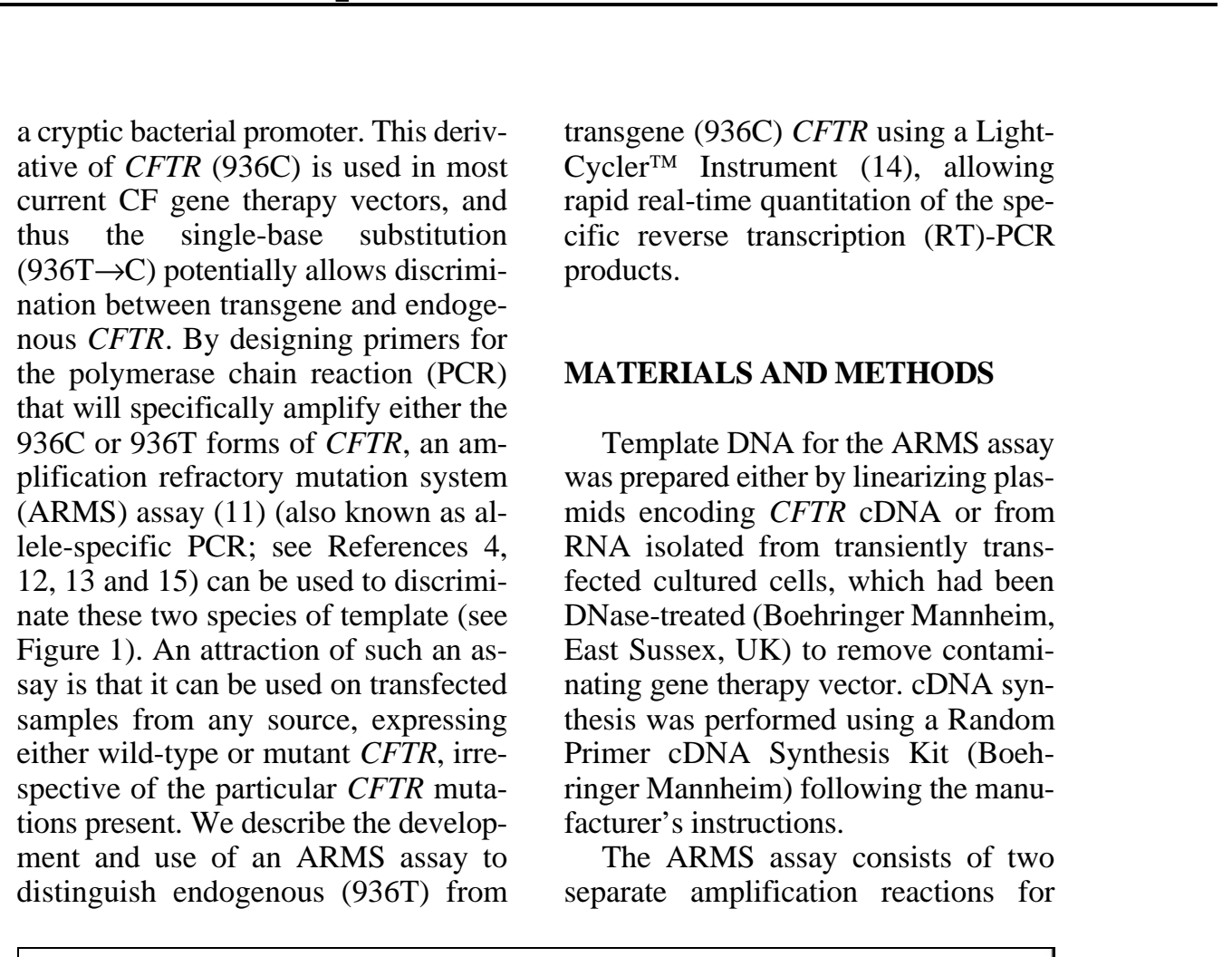

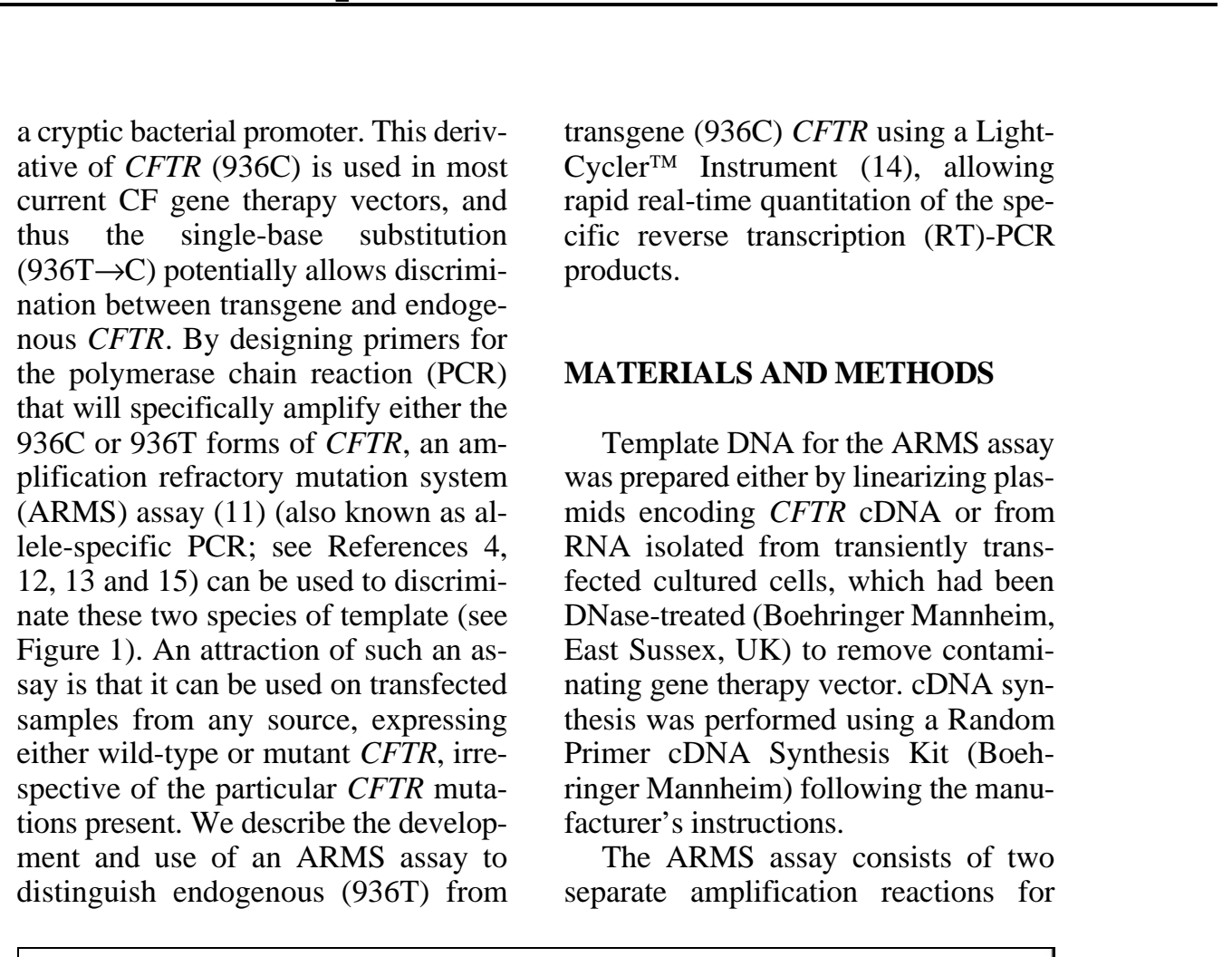

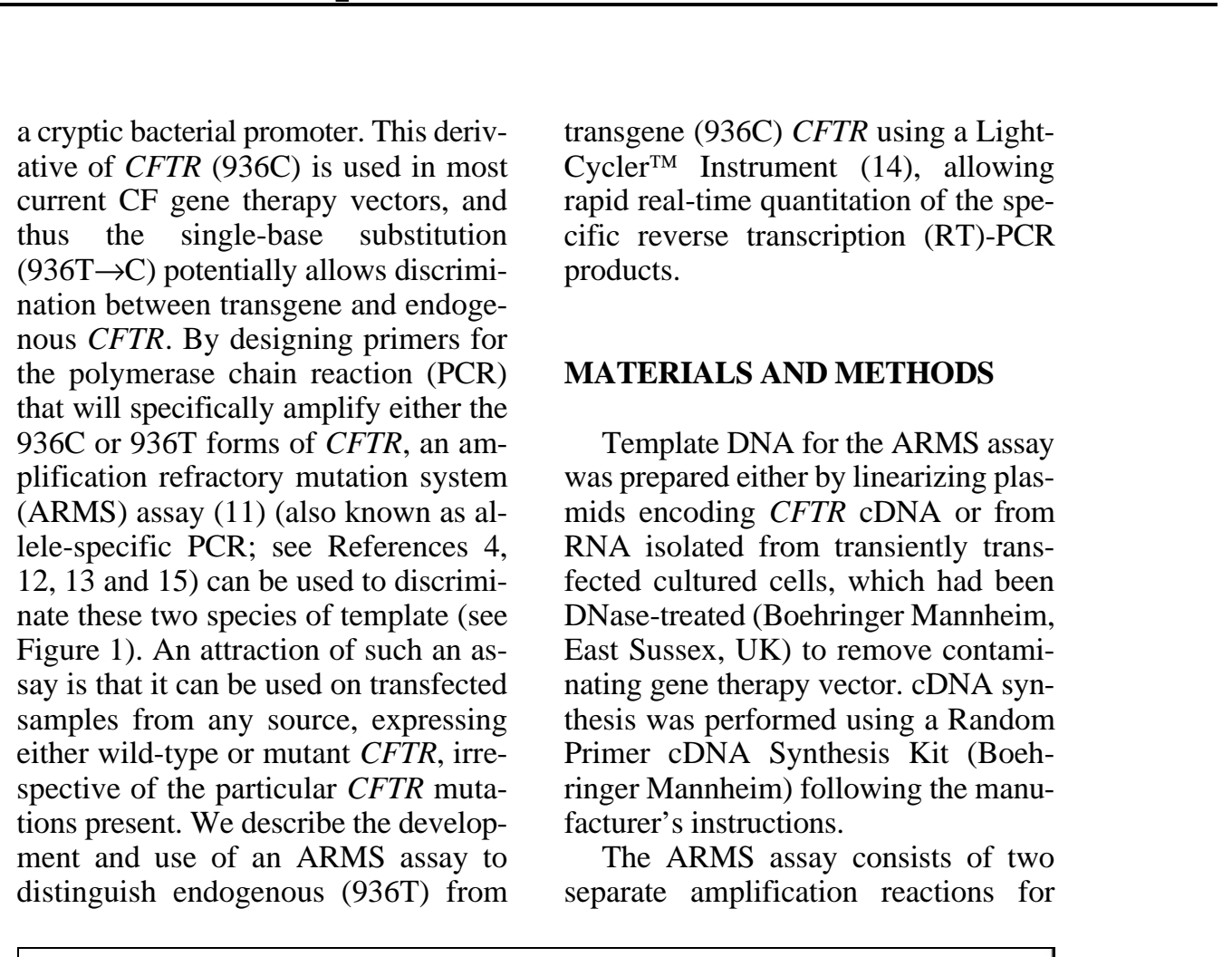

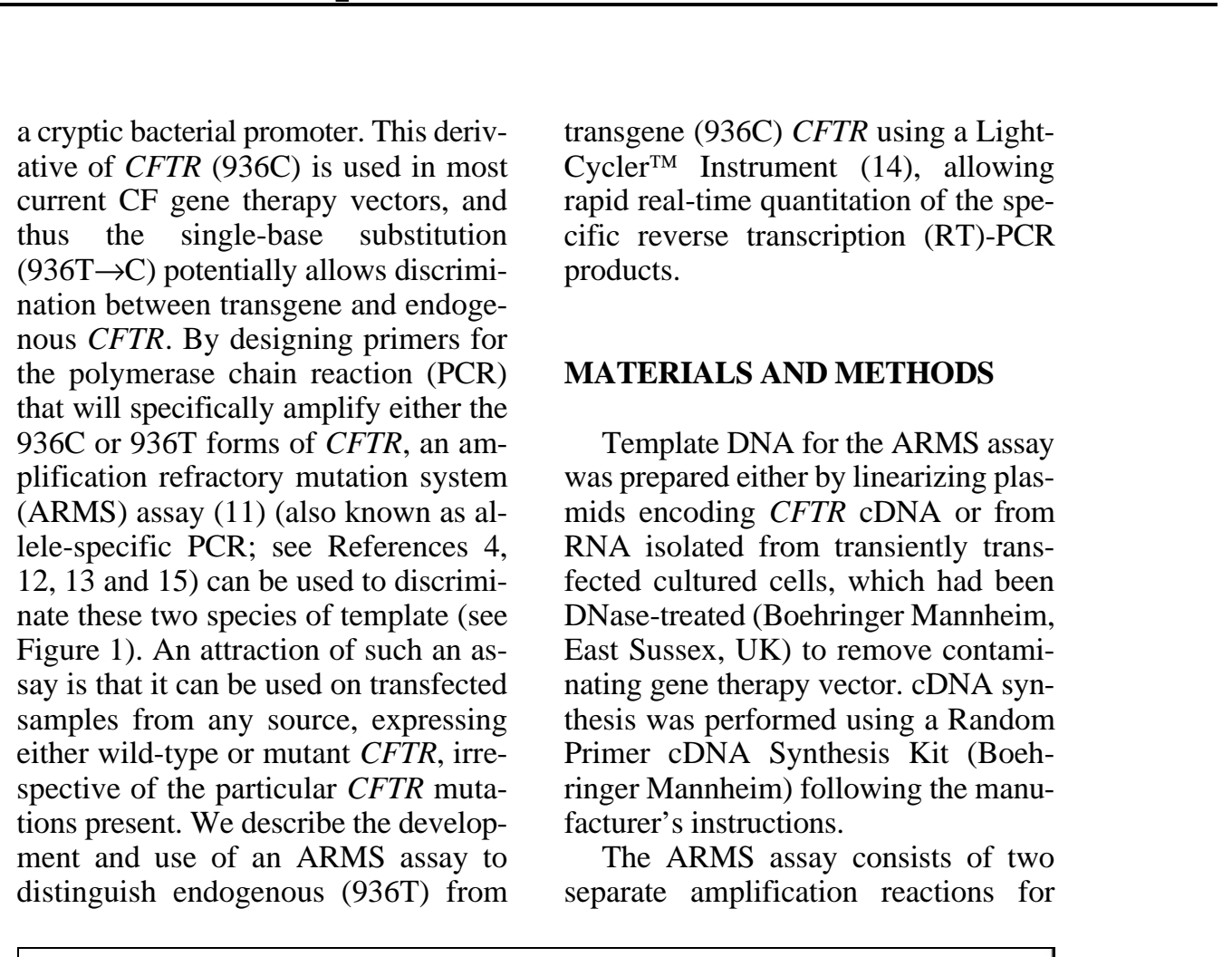

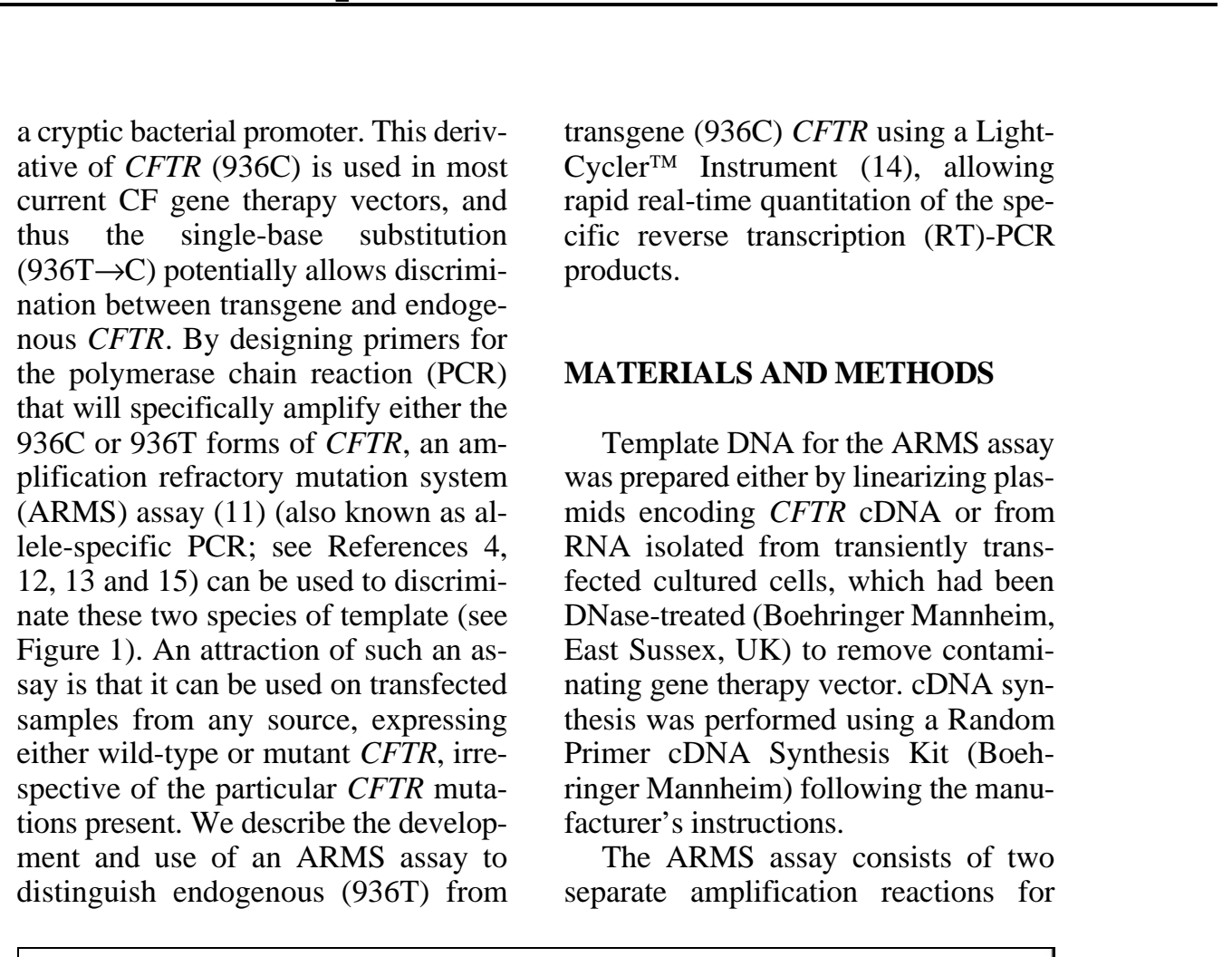

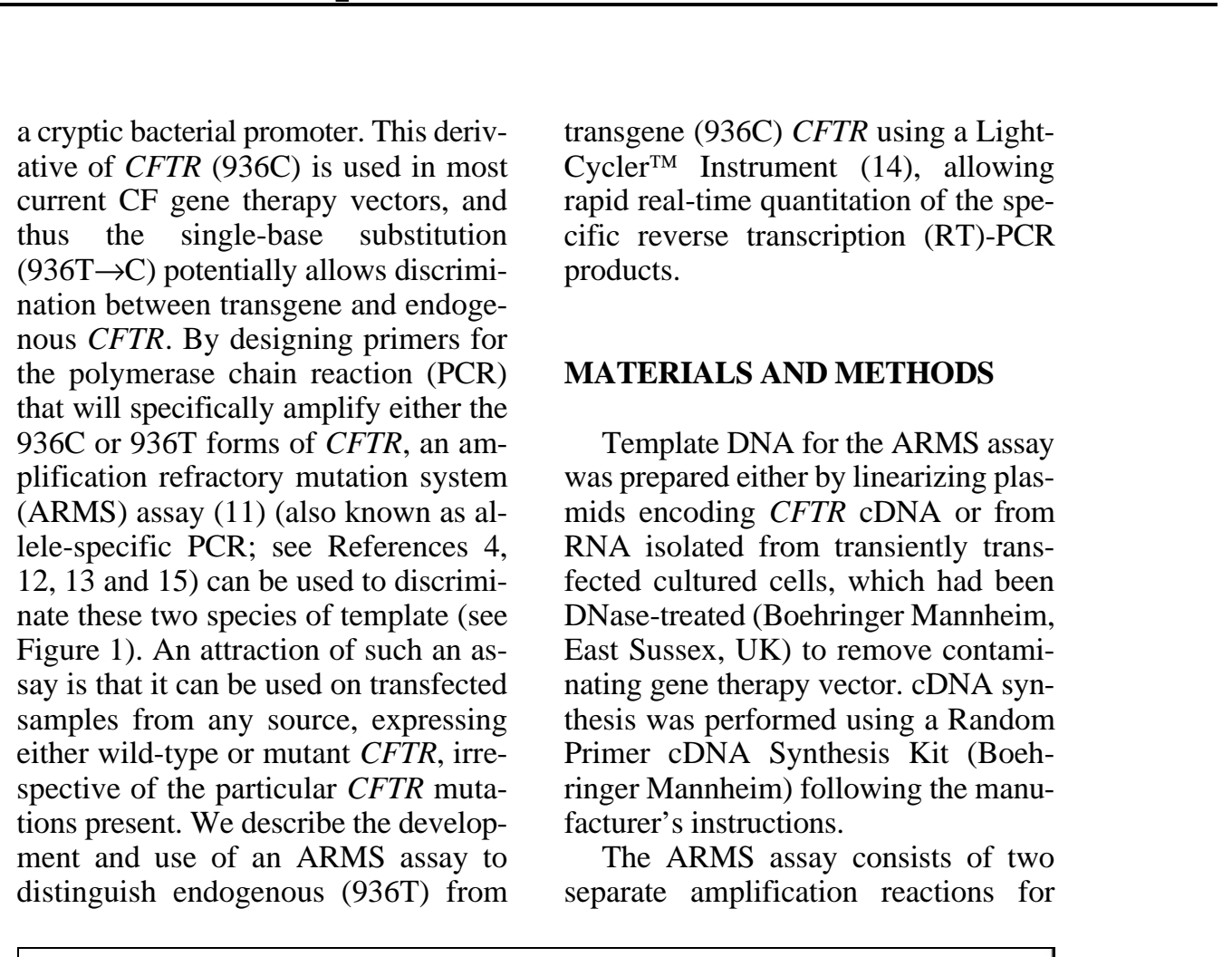

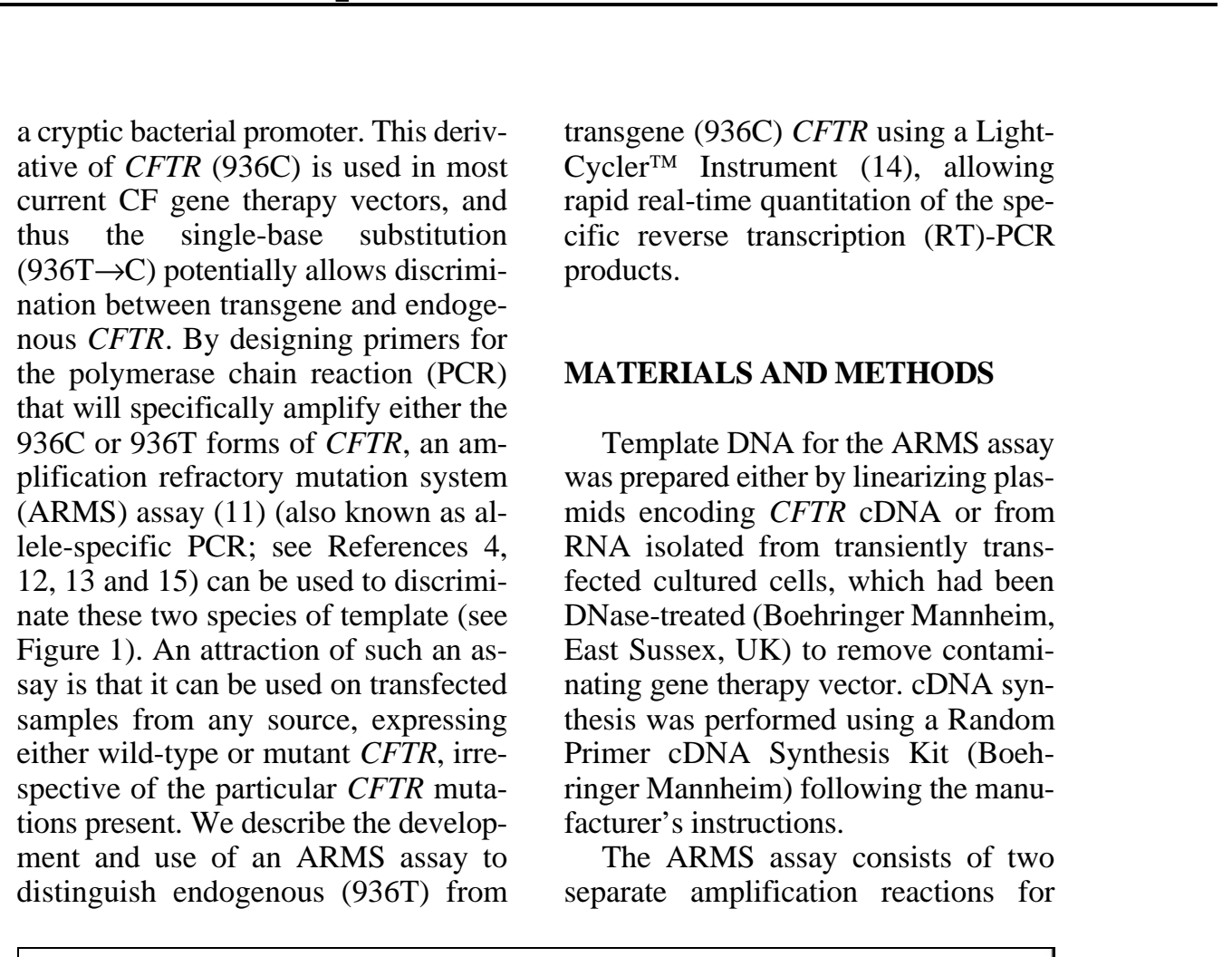

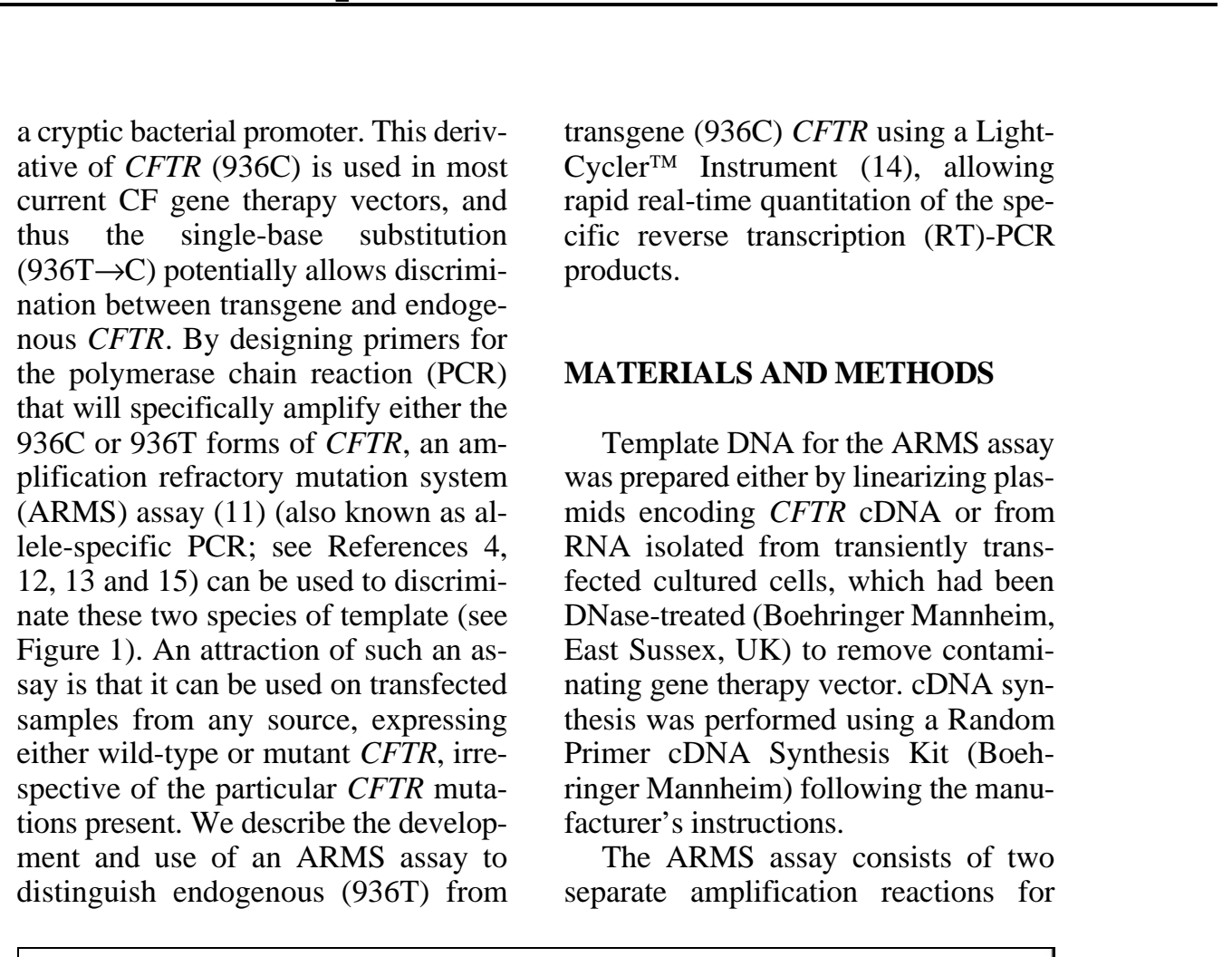

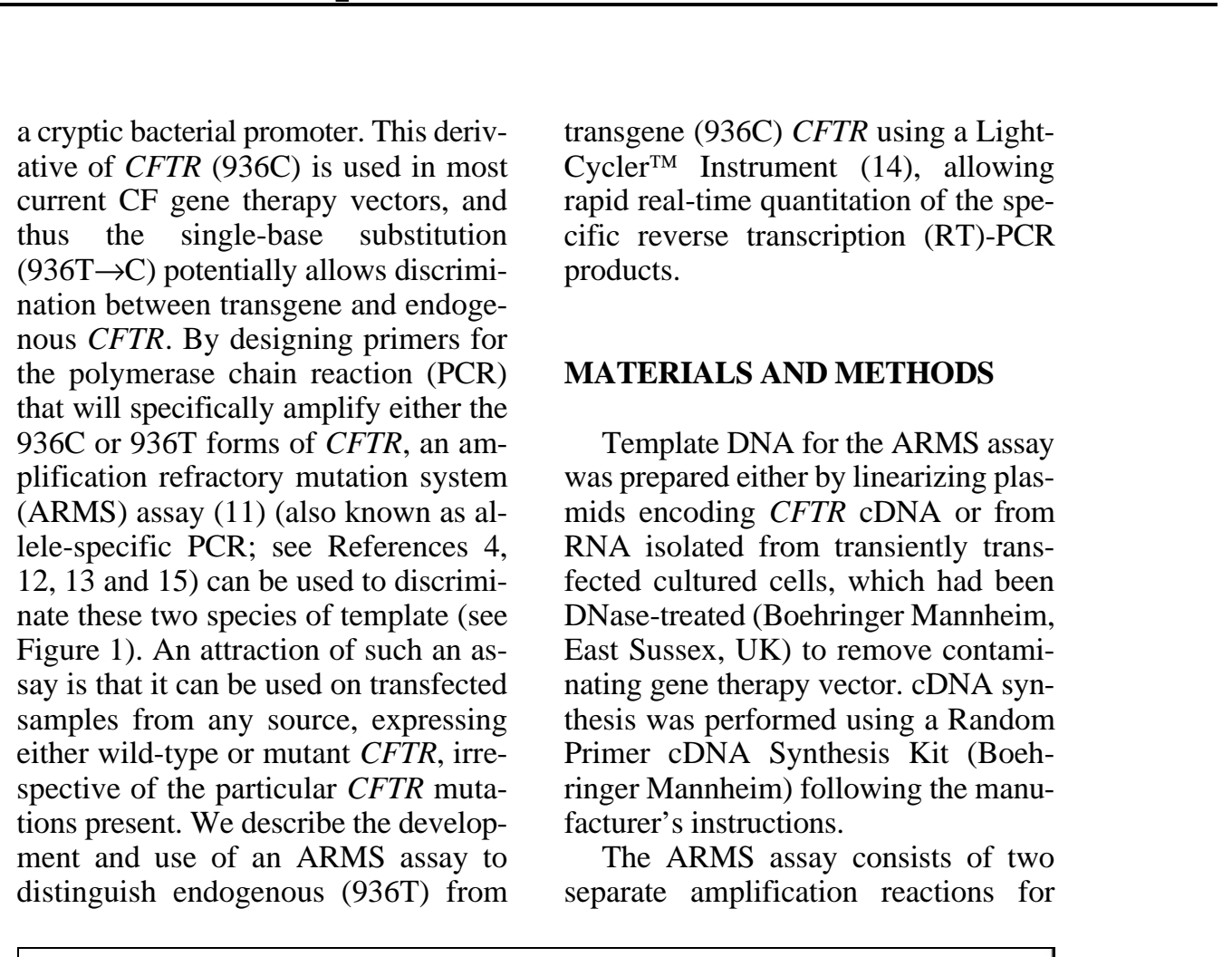

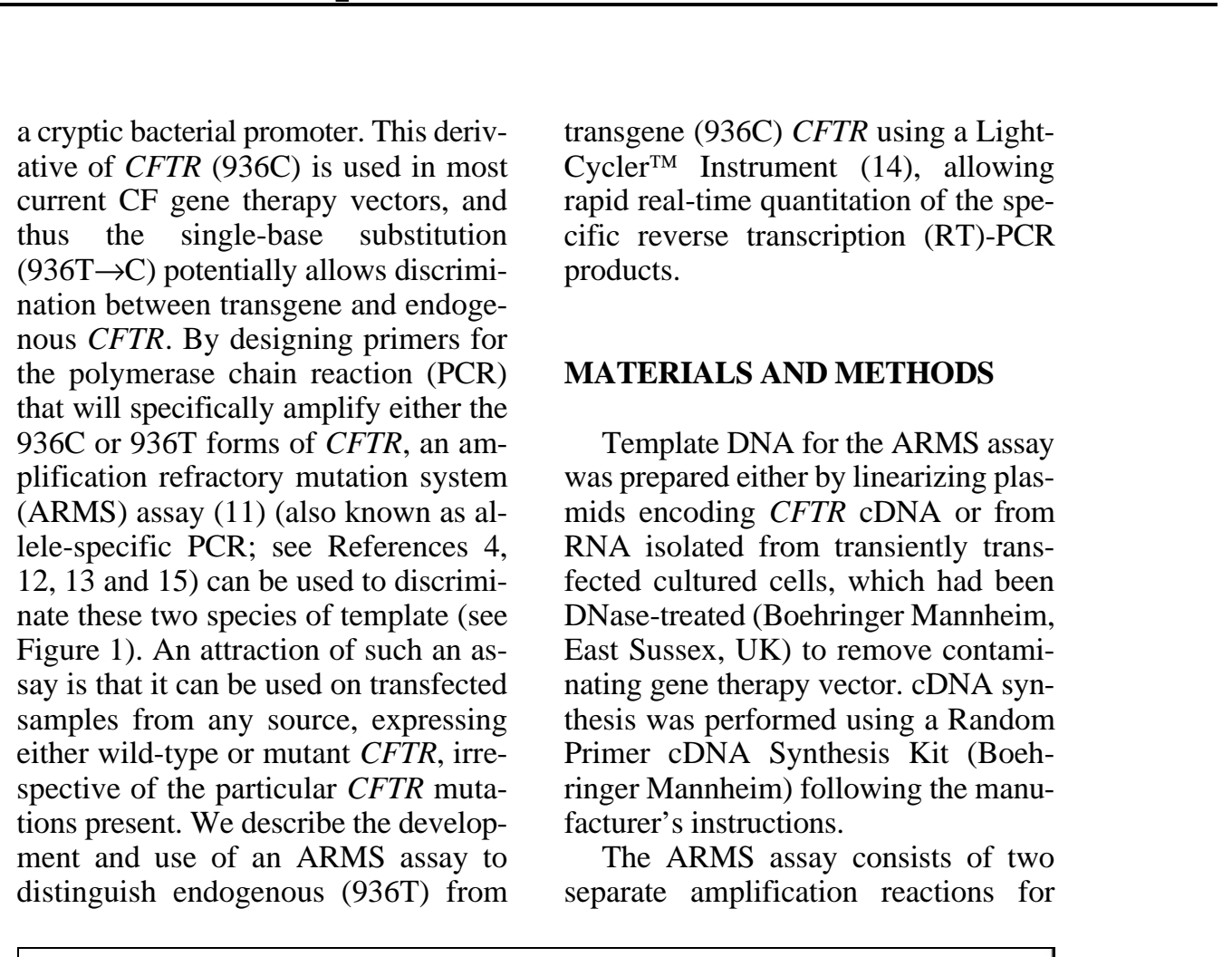

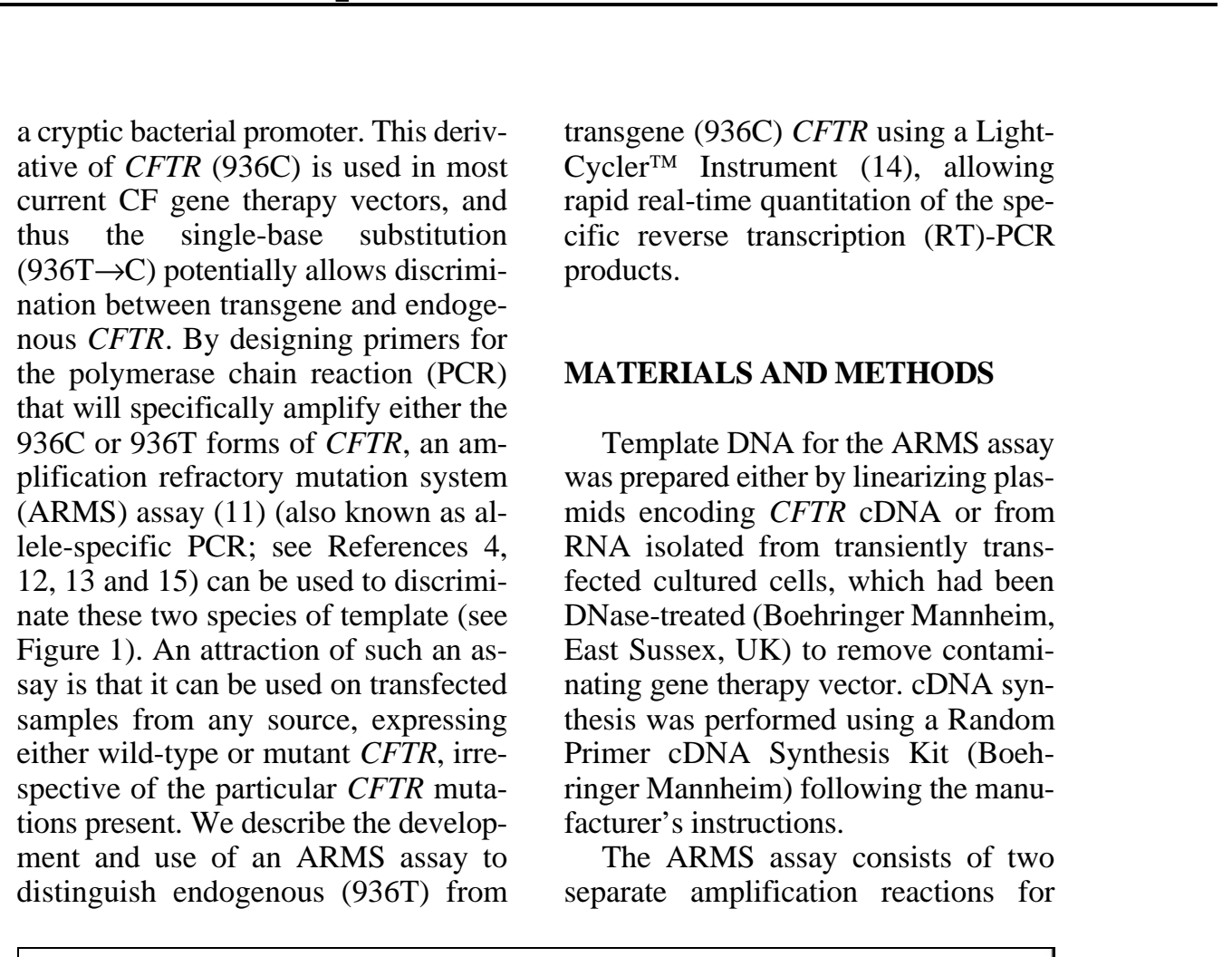

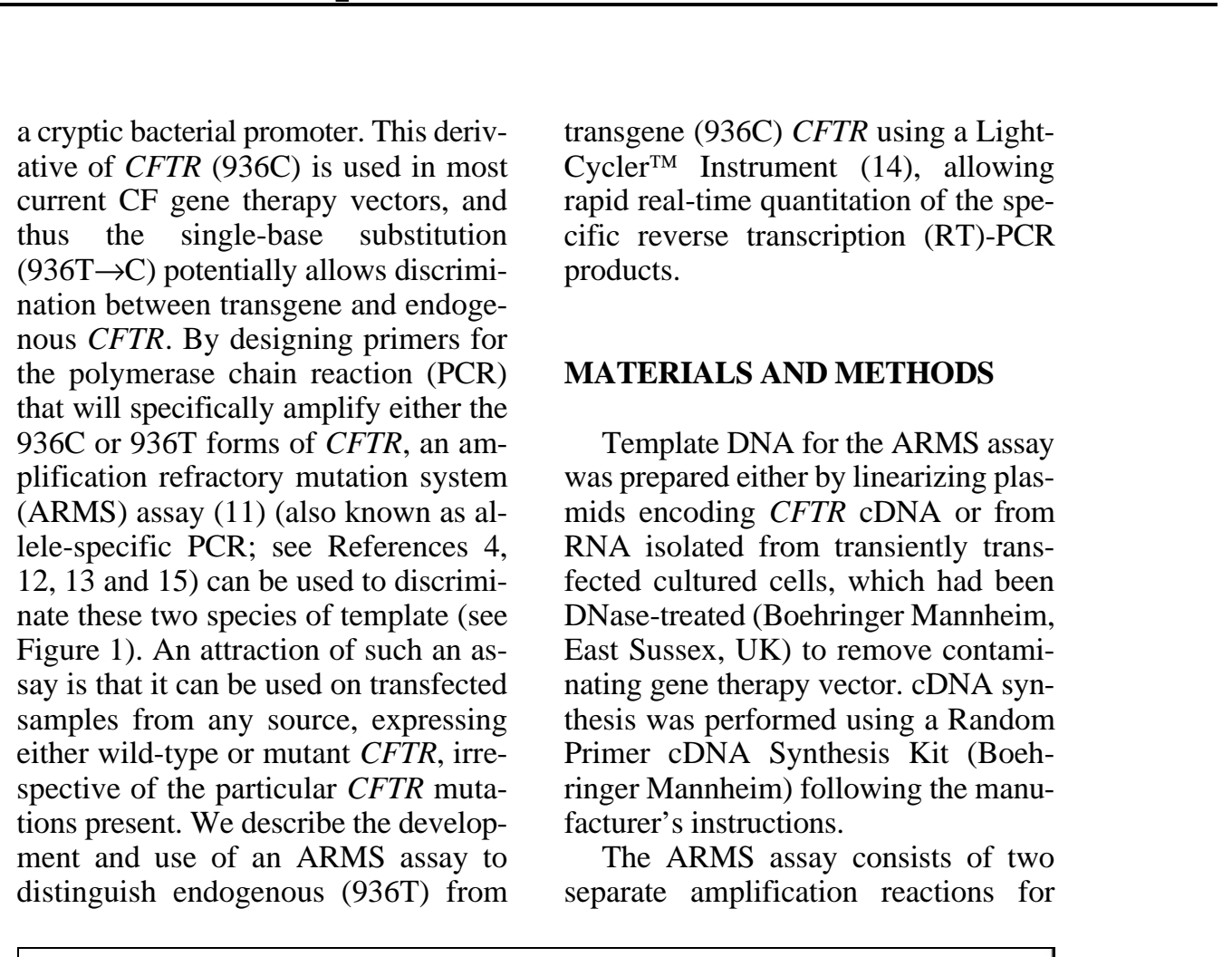

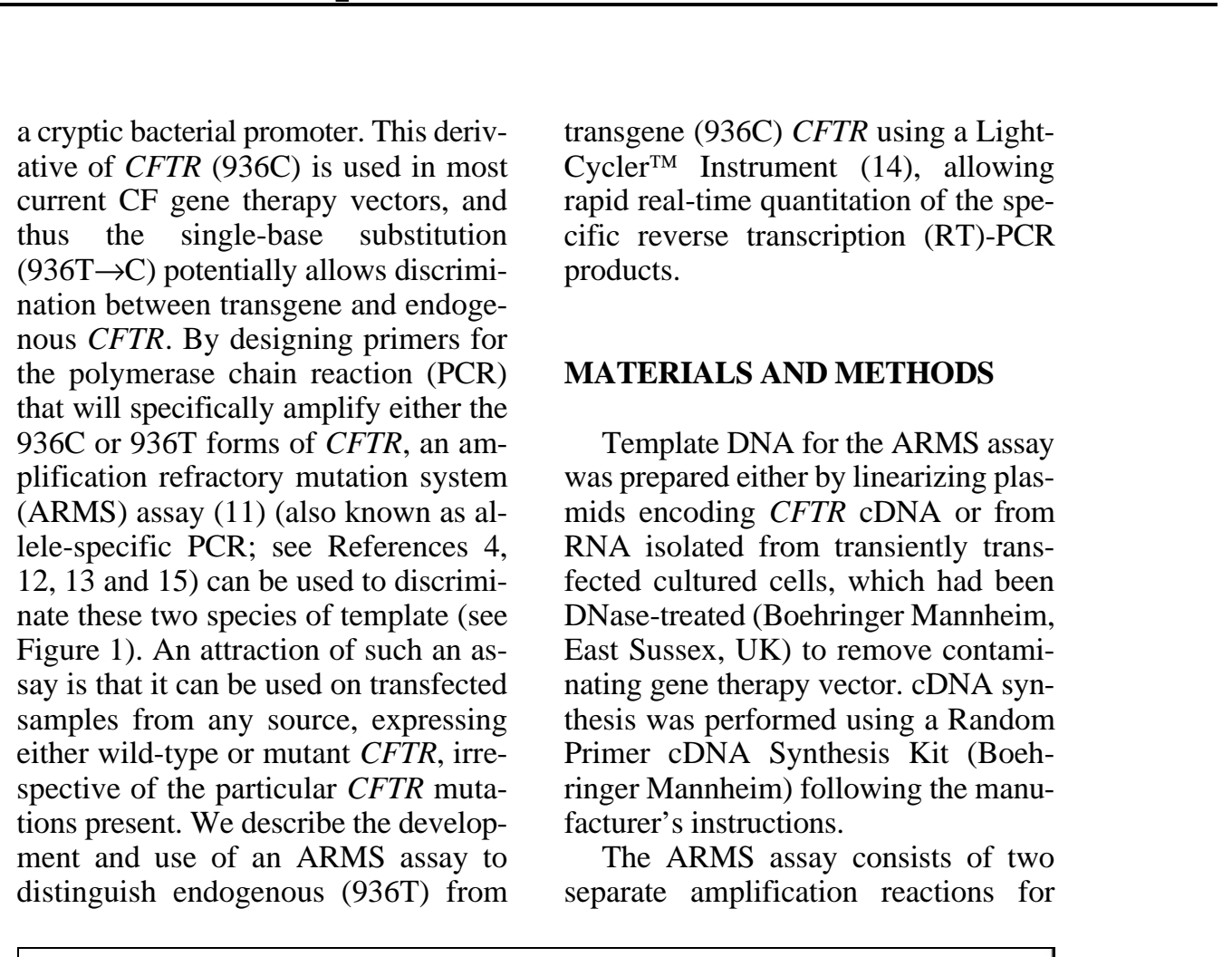

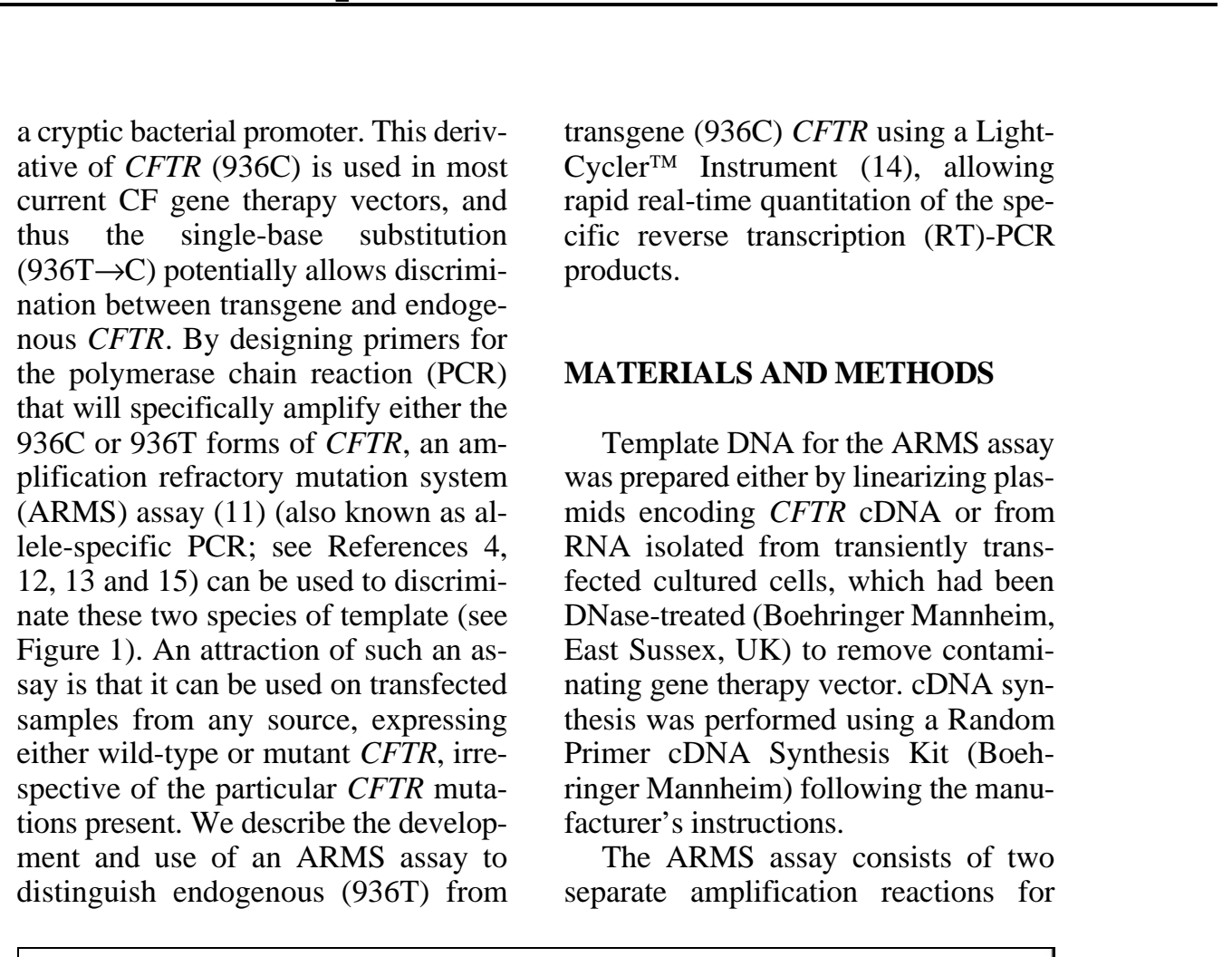

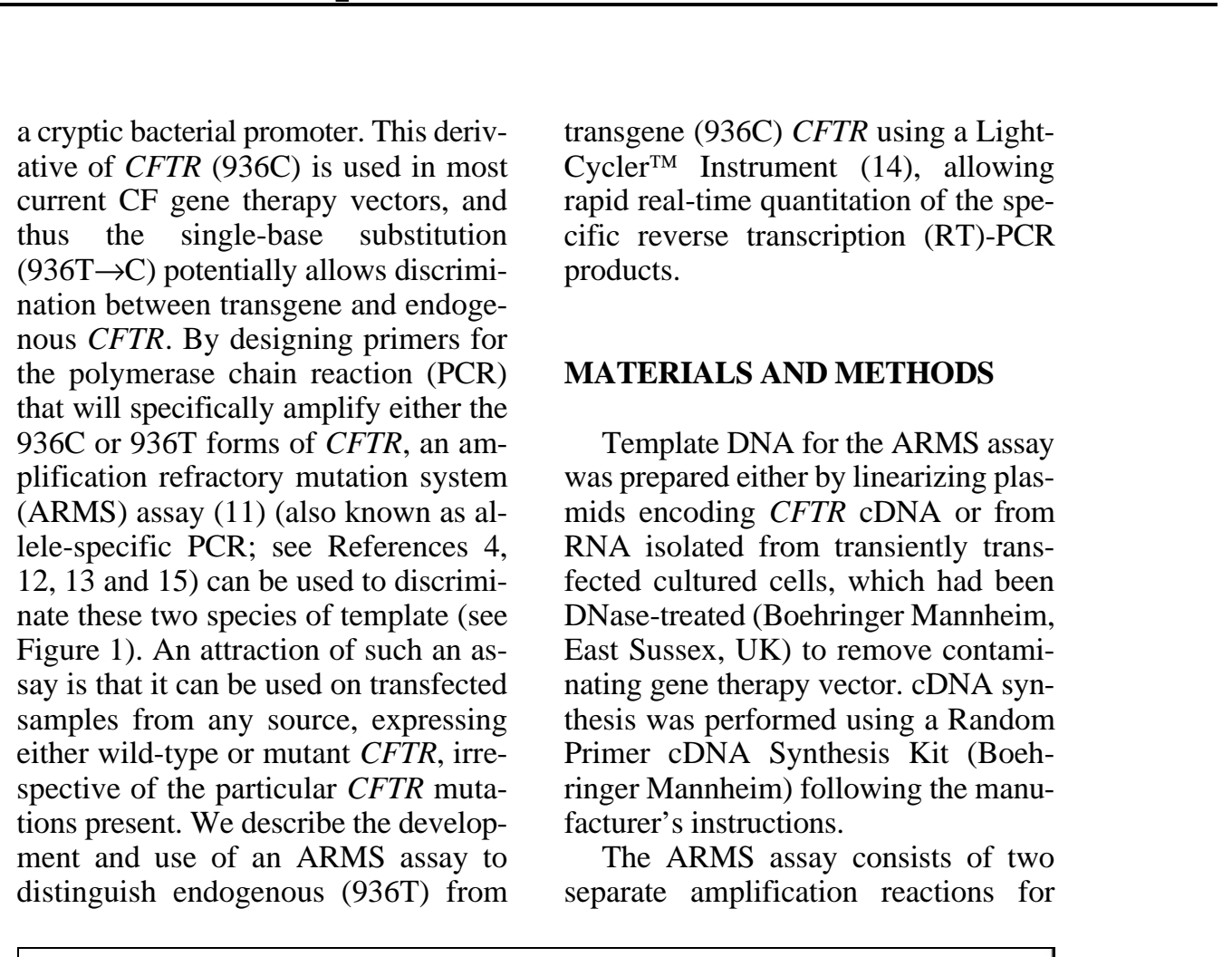

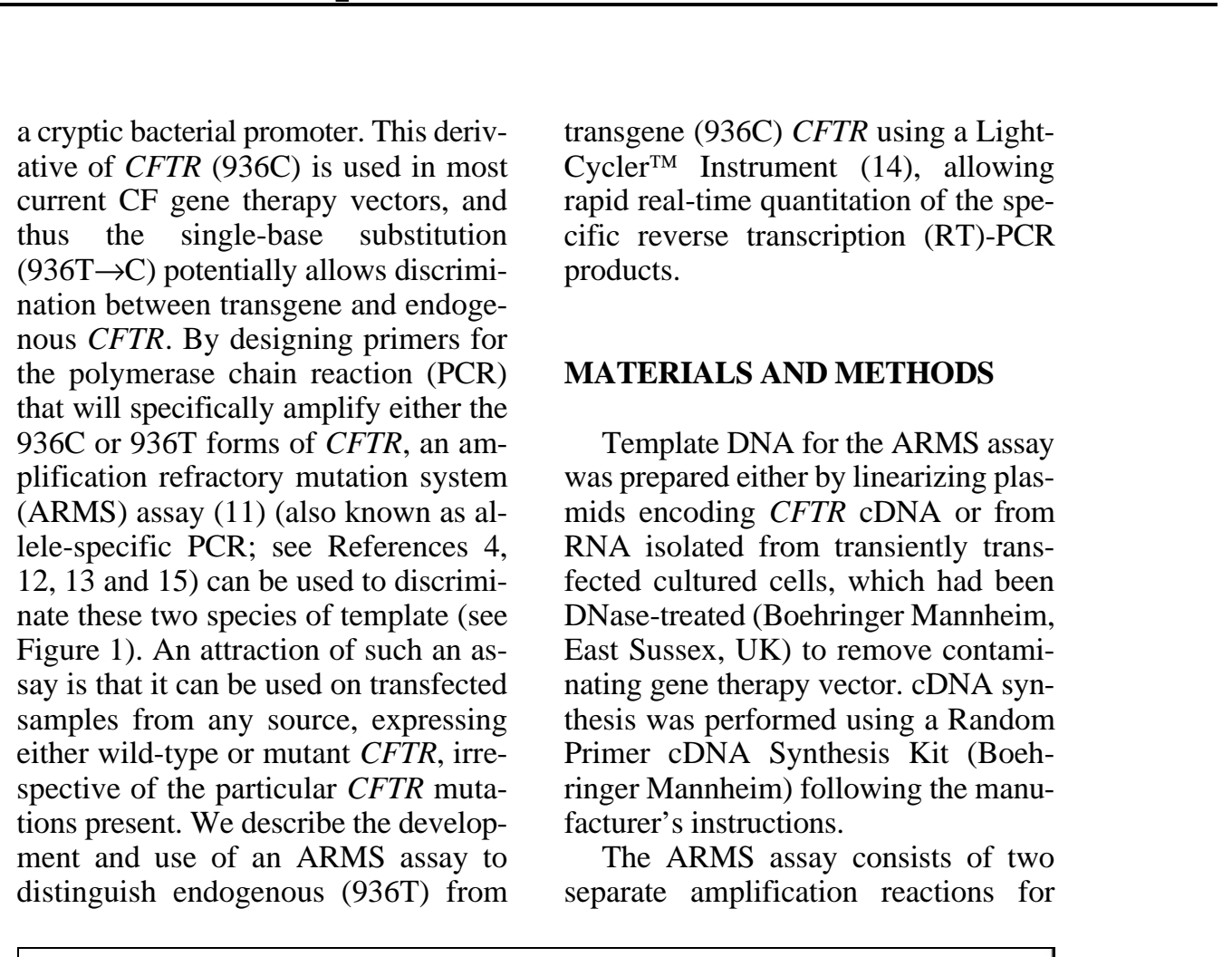

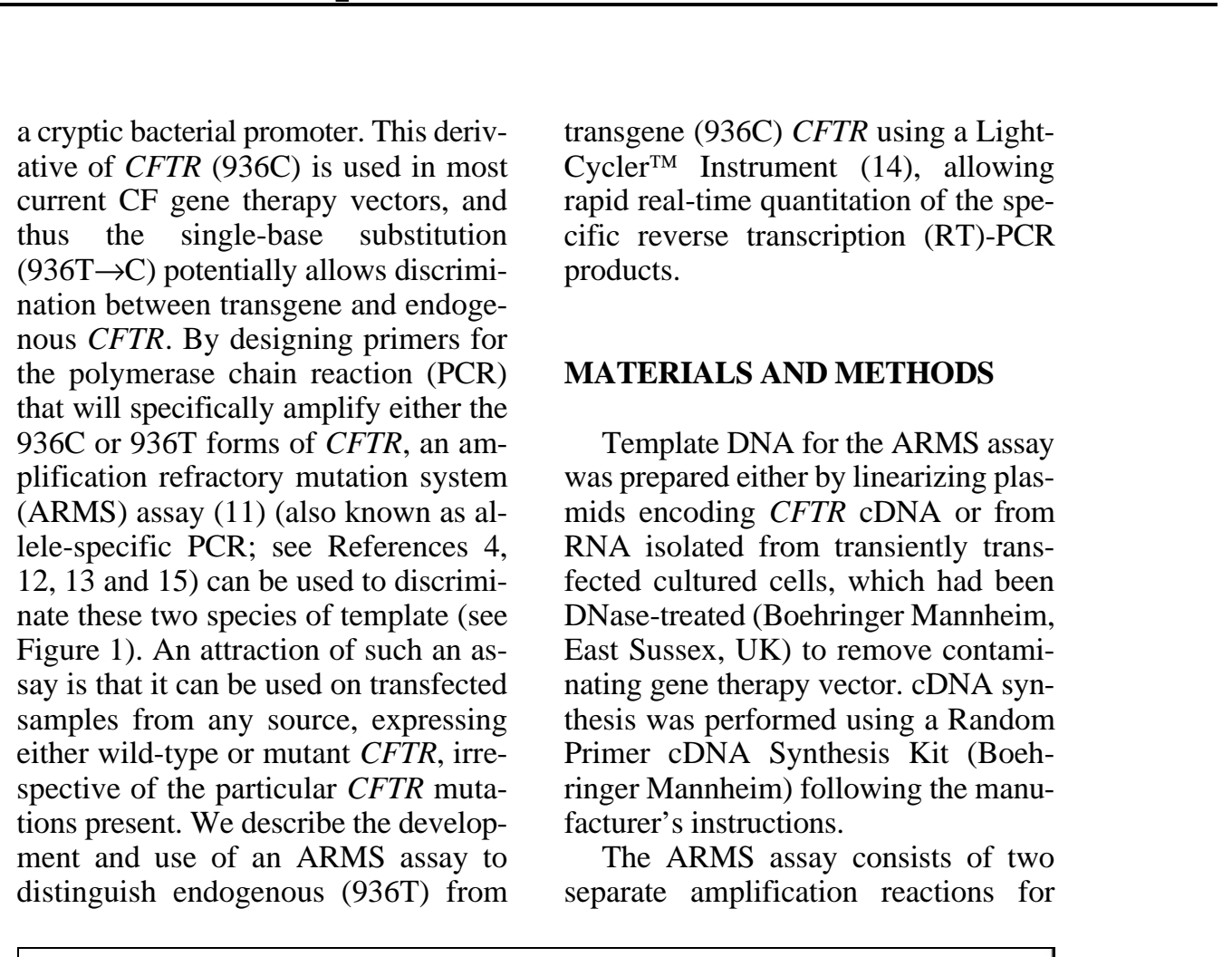

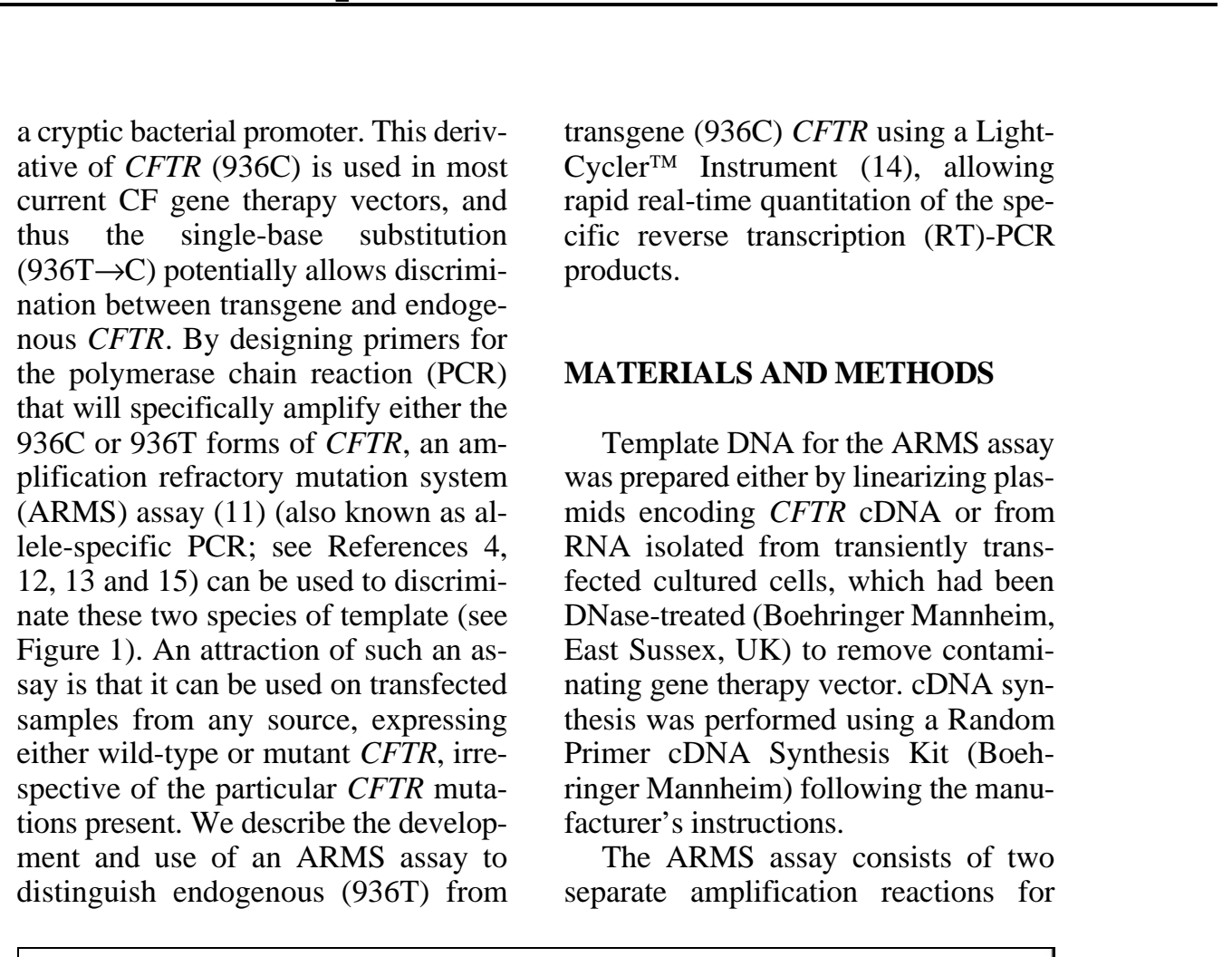

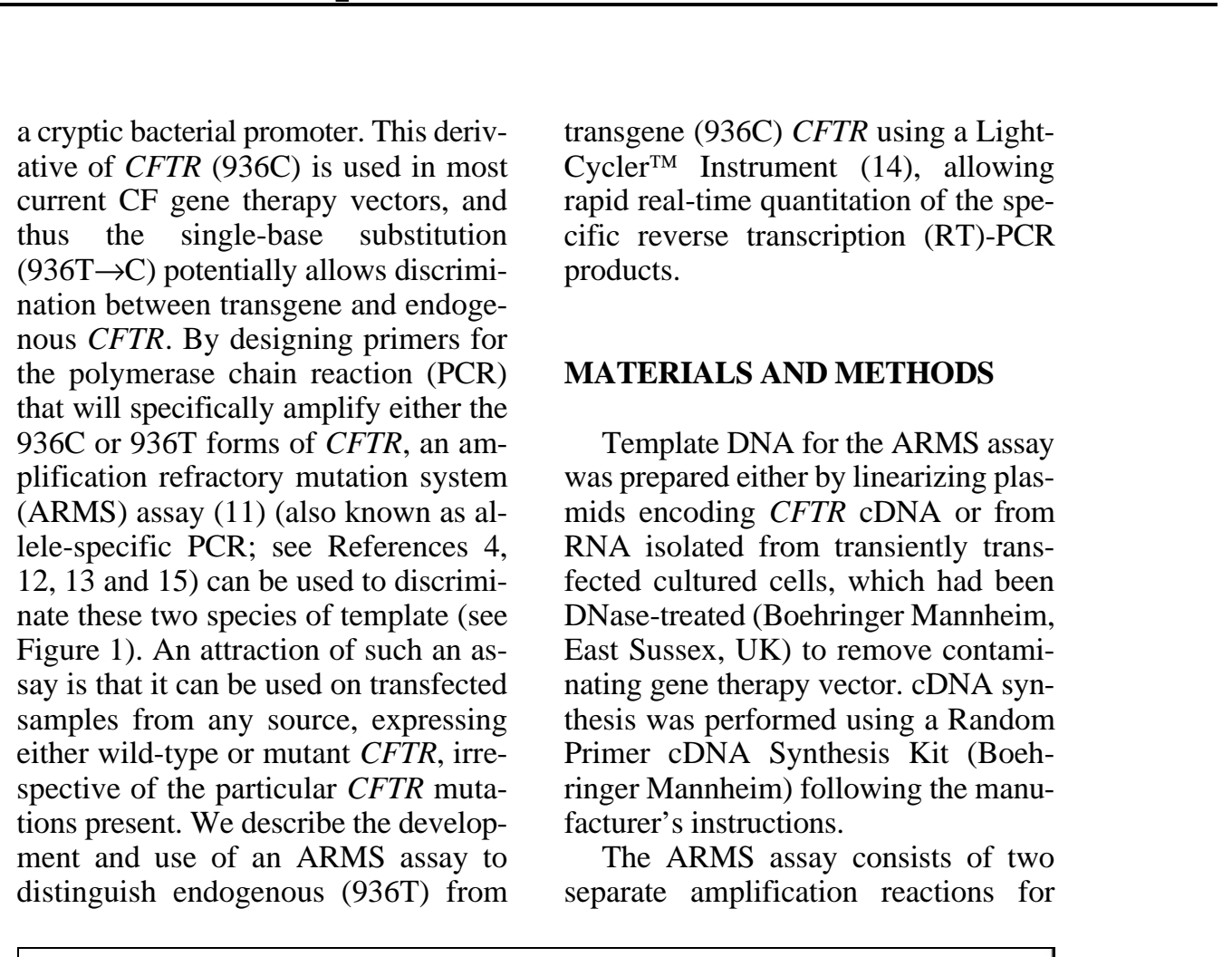

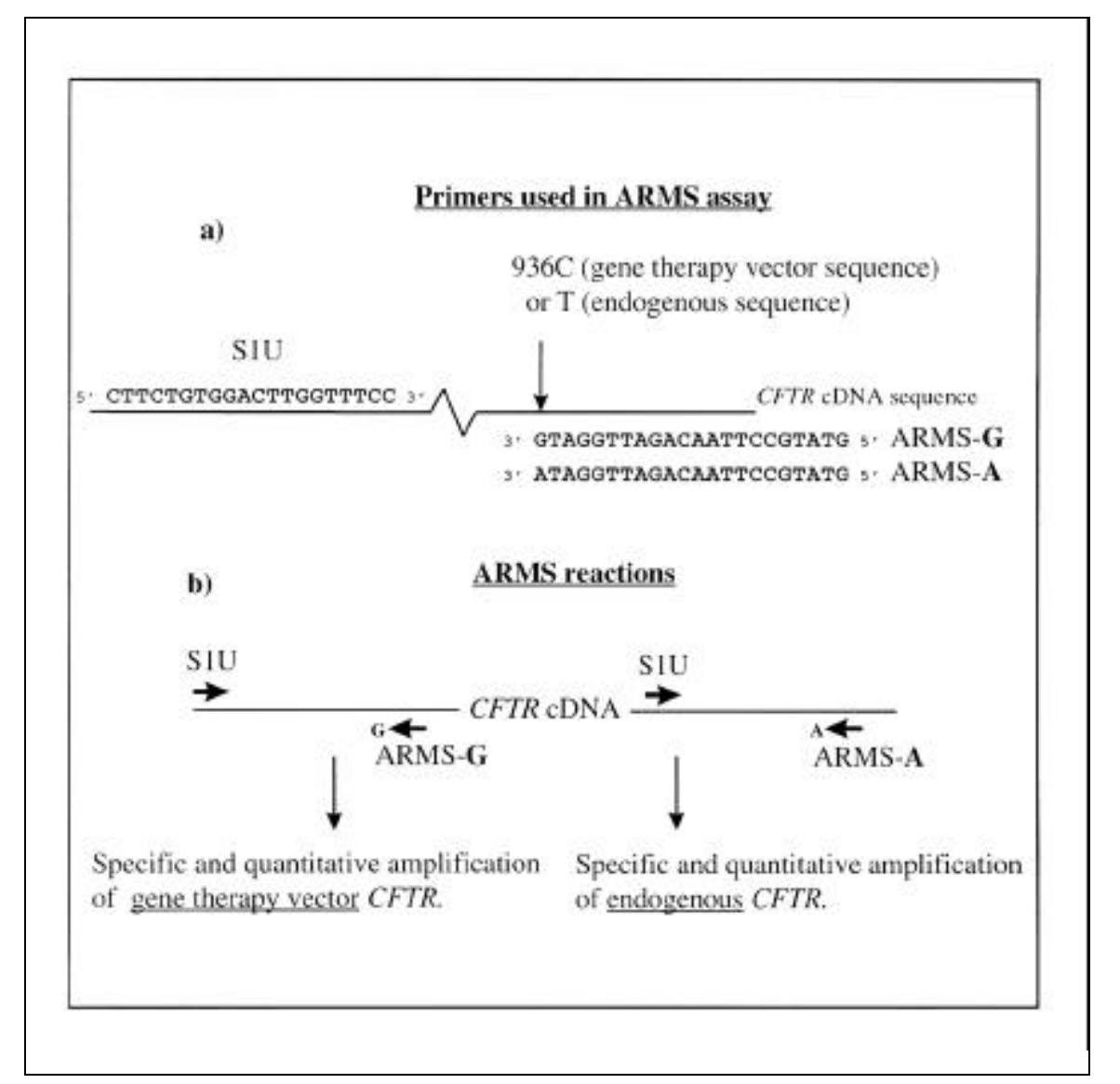

Figure 1. The amplification refractory mutation system. (a) The primers used for the ARMS assay are shown along with a diagram of their hybridization positions on CFTR cDNA. ARMS-G and ARMSA differ by only a single base at their $3^{\prime}$ ends, which hybridizes to the 936 position of CFTR (ARMS-G identical to 936C and ARMS-A identical to 936T). S1U hybridized to both forms of CFTR. (b) The two $C F T R$ cDNAs are represented along with their specific ARMS primers. ARMS-G specifically amplifies transgene (936C), whereas ARMS-A specifically amplifies endogenous (936T) CFTR. 
Table 1. Quantitation of Endogenous and Transgene CFTR Using the ARMS Assay

\begin{tabular}{|c|c|c|c|}
\hline $\begin{array}{l}\text { Sample } \\
\text { No. }\end{array}$ & $\begin{array}{l}\text { No. of Transgene } \\
\text { CFTRTemplate } \\
\text { Molecules }{ }^{\text {a Added }}\end{array}$ & $\begin{array}{l}\text { Assay's Predicted } \\
\text { No. of Transgene } \\
\text { CFTR Molecules }\end{array}$ & $\begin{array}{l}\text { Assay's Predicted } \\
\text { No. of Endogenous } \\
\text { CFTR Molecules' }\end{array}$ \\
\hline 1 & 10 & $5.9 \times 10^{2}$ & $2.7 \times 10^{4}$ \\
\hline 2 & $10^{2}$ & $1.6 \times 10^{3}$ & $2.7 \times 10^{4}$ \\
\hline 3 & $10^{3}$ & $9.5 \times 10^{2}$ & $2.9 \times 10^{4}$ \\
\hline 4 & $10^{4}$ & $1.1 \times 10^{4}$ & $2.8 \times 10^{4}$ \\
\hline 5 & $10^{5}$ & $1.7 \times 10^{5}$ & $2.6 \times 10^{4}$ \\
\hline 6 & 106 & $8.8 \times 10^{5}$ & $3.3 \times 10^{4}$ \\
\hline 7 & $10^{7}$ & $3.3 \times 10^{7}$ & $2.2 \times 10^{4}$ \\
\hline 8 & $10^{9}$ & $1.2 \times 10^{9}$ & $3.7 \times 10^{6}$ \\
\hline $\begin{array}{l}\text { Mean } \\
\text { squared } \\
\text { errord }\end{array}$ & - & 1.38 & 1.83 \\
\hline \multicolumn{4}{|c|}{$\begin{array}{l}\text { A fixed amount of endogenous CFTR (936T) cDNA is seeded with the follow- } \\
\text { ing: }\end{array}$} \\
\hline \multicolumn{4}{|c|}{$\begin{array}{l}\text { aKnown amounts of transgene CFTR }(936 \mathrm{C}) \text { and the samples analyzed in two } \\
\text { separate reactions. }\end{array}$} \\
\hline \multicolumn{4}{|c|}{$\begin{array}{l}\text { bThe assay measures the amount of transgene present using the ARMS-G and } \\
\text { S1U primers as described-the predicted amounts are shown. }\end{array}$} \\
\hline \multicolumn{4}{|c|}{$\begin{array}{l}\text { CARMS-A and S1U primers are used to quantify endogenous CFTR, and the } \\
\text { predicted amounts are shown. Note that in Sample } 8 \text {, the excess of transgene } \\
\text { CFTR present ( } 10^{9} \text { copies) causes an apparent increase in endogenous CFTR. }\end{array}$} \\
\hline \multicolumn{4}{|c|}{$\begin{array}{l}\text { dThe mean squared error (of concentration) from the standard curve is shown } \\
\text { for each of the two reactions (see Figure 2, for details on standard curve and } \\
\text { mean squared error). }\end{array}$} \\
\hline
\end{tabular}

each sample: one specific for transgene, and the other specific for endogenous CFTR. Primers used were S1U, ARMS$\mathrm{G}$ and ARMS-A [Figure 1; Genosys BioTechnologies (Europe) Ltd., Cambridge, England, UK]. One microliter of the cDNA template was mixed with 9 $\mu \mathrm{L}$ of a mixture, producing final concentration of reagents as follows: 50-200 $\mu \mathrm{M}$ dNTPs, $500 \mathrm{nM}$ primers, 3 $\mathrm{mM} \mathrm{MgCl} 2,50 \mathrm{mM}$ Tris-base (pH 8.3), $1 \mathrm{mg} / \mathrm{mL}$ bovine serum albumin (BSA), $0.1 \mathrm{U}$ Taq DNA Polymerase and 1 in $10^{4}$ dilution of SYBR ${ }^{\circledR}$ Green I (all reagents supplied by Bio-Gene, Kimbolton, Cambs, UK). Five microliters of the mixtures were then placed in a reaction capillary and amplified in a LightCycler (supplied by Bio-Gene for Idaho Technology, Idaho Falls, ID, USA).
Temperature profiles for amplification were optimized for each set of primers: (i) For ARMS-A, $95^{\circ} \mathrm{C}$ for $8 \mathrm{~s}$ followed by $60 \times\left(94^{\circ} \mathrm{C}\right.$ for $0 \mathrm{~s}, 56^{\circ} \mathrm{C}$ for $0 \mathrm{~s}$ and $74^{\circ} \mathrm{C}$ for $4 \mathrm{~s}$ ). The temperature ramp rate was $20^{\circ} \mathrm{C} / \mathrm{s}$, except for the transition from $56^{\circ}$ to $74^{\circ} \mathrm{C}$, which was $6^{\circ} \mathrm{C} / \mathrm{s}$. (ii) For ARMS-G, the conditions are the same as for ARMS-A with the exception that the annealing temperature was $58^{\circ}$ not $56^{\circ} \mathrm{C}$, and the ramp rate from $58^{\circ}$ to $74^{\circ} \mathrm{C}$ was $8^{\circ} \mathrm{C} / \mathrm{s}$. At the end of each extension step $\left(74^{\circ} \mathrm{C}\right)$, the fluorescence of each sample was measured to allow quantitation of the PCR. After the PCR was complete, the products were subjected to a temperature gradient from $74^{\circ}$ to $95^{\circ} \mathrm{C}$ at $0.2^{\circ} \mathrm{C} / \mathrm{s}$ with continuous fluorescence monitoring to produce a melting profile of the 


\section{Short Technical Reports}

products. Quantitative analysis was performed on the LightCycler data according to manufacturer's instructions; standard controls of known concentration were included in each run to produce a standard curve, allowing quantitation of templates. Identical template concentrations are detected amplifying exponentially at equivalent number of cycles in separate reactions (data not shown). However, to minimize errors, a standard curve was produced for each separate reaction to allow quantitation of the unknown samples.

\section{RESULTS}

The assay was used to quantitate either endogenous or transgene CFTR cDNA. cDNA samples from cells expressing endogenous human CFTR were quantified using primers $\mathrm{S} 1 \mathrm{U}$ and ARMS-A. Figure 2 shows quantitation of a cDNA sample of endogenous CFTR relative to known controls. The single unknown sample in this reaction was predicted to contain $2.1 \times 10^{6}$ copies of endogenous CFTR (mean squared error of concentration of 1.45). After the conclusion of the quantitative amplification reactions, the products were melted (as outlined in Materials and Methods). The melting is monitored with fluorescence, which is lost when the double-strand products melt apart. As different DNA products melt at different temperatures, distinguishing genuine products from primer dimers or nonspecific products is possible. The assay could distinguish as few as $10^{2}-10^{3}$ copies of CFTR, below which nonspecific amplification of primer-dimers was seen (for example, see Table 1).

The main strength of this assay however is not in its sensitivity but in its abil- ity to distinguish 936C (transgene) from 936T (endogenous) CFTR. Figure 3 shows an example of this. CFTR $\left(10^{5}\right.$ copies) was amplified with primers (S1U and ARMS-G) specific for transgene CFTR. One sample contains $10^{5}$ copies of 936C transgene CFTR, while the other had an identical concentration of 936T endogenous CFTR (two $\mathrm{H}_{2} \mathrm{O}$ controls are included). Only the transgene CFTR is amplified, showing that the PCR is specific for transgene sequence.

The assay could be used to analyze a mixture of both endogenous and transgene $C F T R$, such as we might find in a cDNA sample from a clinical trial. To model this situation, samples of a fixed concentration of endogenous CFTR cDNA were seeded with known concentrations of transgene CFTR. The absolute quantities of both species were assayed with their respective specific

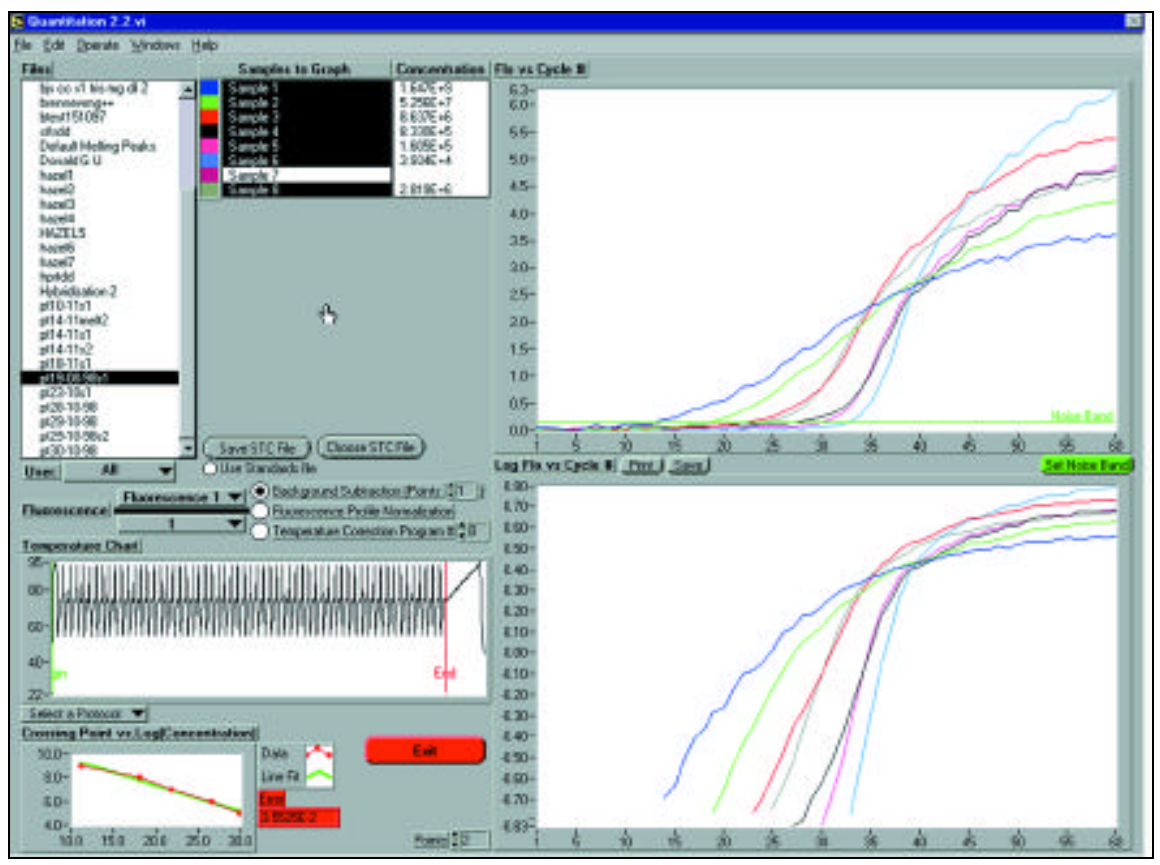

Figure 2. Quantitation of endogenous CFTR. A screen of the LightCycler quantitation software for six different amounts of endogenous $C F T R$; also included is a sample of unknown concentration. The primers used (ARMS-A and S1U) are specific for the endogenous CFTR (936T). The panels are labeled (from top left clockwise): 'Files', the particular reaction selected. 'Samples to Graph', samples are as follows: samples 1-6 contain various control quantities of endogenous $C F T R$, presented as absolute numbers of CFTR molecules; sample $1=10^{9}$, sample $2=10^{8}$, sample $3=10^{7}$, sample $4=10^{6}$, sample $5=$ $10^{5}$ and sample $6=10^{4}$; sample 8 contains an unknown quantity of endogenous CFTR (sample 7 is not shown). 'Concentration', the predicted concentration based upon the standard curve (bottom left) for all samples, including those of known concentration; sample 8 is predicted to contain $2.1 \times 10^{6}$ copies of CFTR. The two graphs demonstrate the following: (i) 'Flo v. Cycle \#' shows the SYBR Green I fluorescence (relative units) on the y-axis and PCR cycle number on the x-axis; and (ii) 'Log Flo vs. Cycle \#' shows $\log$ fluorescence against PCR cycle number. 'Crossing Point vs. Log (Concentration)', the standard curve for this data with the six known controls; the actual data points are shown in red, and the standard curve is shown in green. The mean squared error of $\log$ (concentration) of the data vs. the standard curve is shown in red immediately right of the graph (in this case 0.16 ; hence, the mean squared concentration error is 1.45). The 'Temperature Chart', the temperature profile of the entire PCR. 


\section{Short Technical Reports}

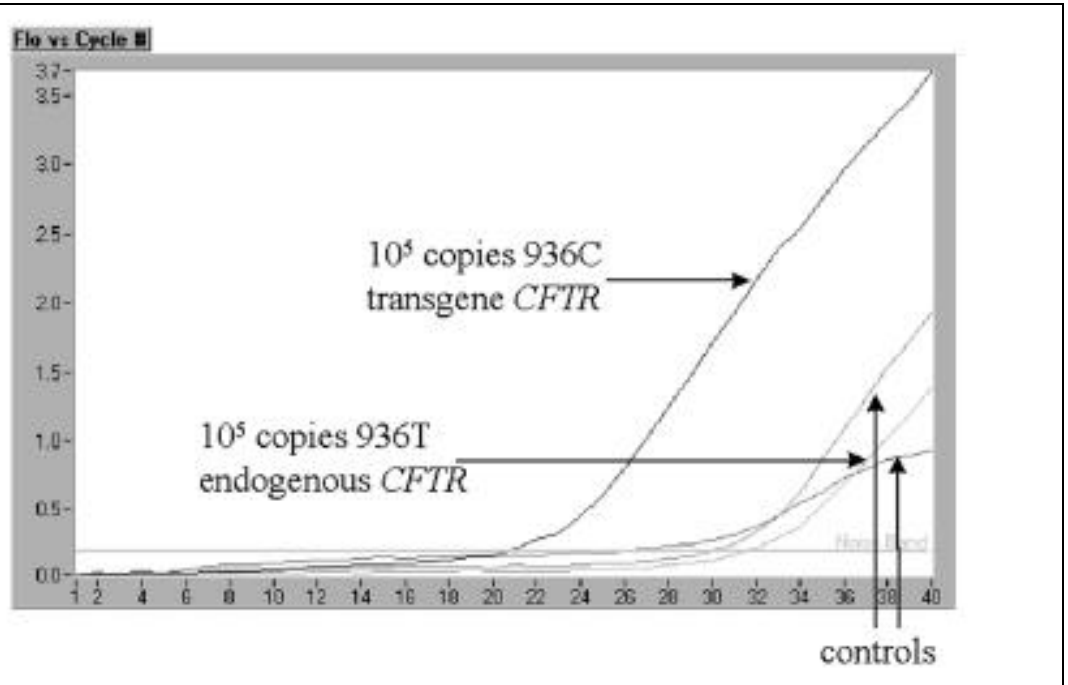

Figure 3. Distinguishing transgene from endogenous $C F T R$. This figure shows the 'Flo vs. Cycle \#' section of the quantification software (compare with Figure 2). SYBR Green I fluorescence (in relative units) is plotted on the $\mathrm{y}$-axis against PCR cycle number on the $\mathrm{x}$-axis. The primers used in this reaction are ARMS-G and S1U; hence, this reaction is specific for the transgene (936C) CFTR. Four samples are shown: two are $\mathrm{H}_{2} \mathrm{O}$ controls, and these seem to amplify (primer-dimer amplification) at approximately the same position as $10^{5}$ copies of endogenous CFTR; whereas $10^{5}$ copies of transgene amplify over 10 cycles earlier in the reaction. Thus the assay discriminates between transgene and endogenous CFTR. primers. Table 1 shows the results of the assay relative to the known concentrations used. This demonstrates the ability of our assay to compare levels of cDNA in a mixture of the two species (endogenous and transgene).

\section{DISCUSSION}

Detection of CFTR transcripts using RT-PCR is a standard method for assessing the efficiency of gene therapy. In experiments using CF mouse models, the primers can be designed specifically for the human sequence, thereby eliminating problems associated with endogenous CFTR. In human cell lines or in clinical trials, endogenous and exogenous $C F T R$ will be co-amplified, as the template CFTR sequences are identical. Mayall and Coutelle (10) exploited the presence of the simian virus 40 (SV40) small T-antigen intron in their gene 
therapy vector to distinguish transgene signal from both DNA and endogenous message in RT-PCRs; however, such mechanisms limit vector choice and rely on the presumption of efficient splicing. The presence of the $\mathrm{T} \rightarrow \mathrm{C}$ base change, at position 936 in the cDNA, allows another way of discriminating between genomic- and vector-derived expression by virtue of the fortuitous creation of a FokI site in 936C CFTR. Hence, appropriate PCR products can be digested with FokI, and the resulting fragments quantified to determine the ratio of genomic-to-vector transcript. However, this is laborious and relies on full cleavage of the $936 \mathrm{C}$ product. A different restriction assay developed by Hart et al. (6), introduced two silent mutations into CFTR to allow restriction digests of PCR products for quantitation. Proofreading PCR (2) could also be used to make the discrimination; although, variation in efficiency of polymerase proofreading could compromise quantitation.

The ARMS assay makes use of the single base pair difference engineered into transgene CFTR cDNA (5) in a simple and direct way to prevent amplification of the nonspecific product. An excess of $10^{3}$ copies of one template species over the other could be detected, beyond which, mis-amplification of the nonspecific template was seen. This is in agreement with published mis-incorporation rates of Taq DNA polymerase $(7,8)$. Fluorescent monitoring of PCR can be optimized to enable detection of a single-template molecule (9); although, the sensitivity of our assay is limited because of constraints in primer design and in our use of SYBR Green I for PCR product detection. However, it provides a quantitative assessment of transgene mRNA levels both in absolute terms and in comparison with the level of endogenous CFTR in the range and relative ratio likely to be encountered experimentally and in clinical trials. The analysis of 24 samples (including controls) takes less than 20 min, allowing a simple and rapid way to quantify CFTR cDNA from in vitro and in vivo experiments.

\section{REFERENCES}

1.Alton, E.W.F.W., D.M. Geddes, D.R. Gill,
C.F. Higgins, S.C. Hyde, J.A. Innes and D.J. Porteous. 1998. Towards gene therapy for cystic fibrosis: a clinical progress report. Gene Ther. 5:291-292.

2.Bi, W. and P.J. Stambrook. 1998. Detection of known mutation by proof-reading PCR. Nucleic Acids Res. 26:3073-3075.

3.Davies, J.C., D.M. Geddes and E.W.F.W. Alton. 1998. Prospects for gene therapy for cystic fibrosis. Mol. Med. Today 4:292-299.

4.Ehlen, T. and L. Dubeau. 1989. Detection of ras point mutations by polymerase chain reaction using mutation specific, inosin-containing oligonucleotide primers. Biochem. Biophys. Res. Commun. 160:441-447.

5.Gregory, R.J., S.H. Cheng, D.P. Rich, J. Marshall, S. Paul, K. Hehir, L. Ostedgaard, K.W. Klinger, M.J. Welsh and A.E. Smith. 1990. Expression and characterization of the cystic fibrosis transmembrane regulator. Nature 347:382-386.

6.Hart, S.L., E. Mayall, M. Stern, F.M. Munkonge, A. Frost, L. Huang, M. Vasilliou, R. Williamson, E.W.F.W. Alton and C. Coutelle. 1995. The introduction of two silent mutations into a CFTR cDNA construct allows improved detection of exogenous mRNA in gene transfer experiments. Hum. Mol. Genet. 4:1597-1602.

7.Huang, M.M., N. Arnheim and M.F. Goodman. 1992. Extension of base mispairs by Taq DNA polymerase: implications for single nucleotide discrimination in PCR. Nucleic Acids Res. 20:4567-4573.

8.Kwok, S., D.E. Kellogg, N. McKinney, D. Spasic, L. Goda, C. Levenson and J.J. Sninsky. 1990. Effects of primer-template mismatches on the polymerase chain reaction: human immunodeficiency virus type I model studies. Nucleic Acids Res. 18:999-1005.

9.Lockey, C., E. Otto and Z. Long. Real-time fluorescence detection of a single DNA molecule. BioTechniques 24:744-746.

10.Mayall, E.S. and C. Coutelle. 1997. RT-PCR method specific for the detection of transgenic CFTR mRNA in the presence of transgene plasmid DNA and endogenous CFTR mRNA. Gene Ther. 4:875-878.

11.Newton, C.R., A. Graham, L.E. Heptinstall, S.J. Powell, C. Summers, N. Kalsheker, J.C. Smith and A.F. Markham. 1989. Analysis of any point mutation in DNA. The amplification refractory mutation system (ARMS). Nucleic Acids Res. 17:2503-2516.

12.Okayama, H., D.T. Curiel, M.L. Brantly, M.D. Holmes and R.G. Crystal. 1989. Rapid, nonradioactive detection of mutations in the human genome by allele-specific amplification. J. Lab. Clin. Med. 114:105-113.

13.Ugozzoli, L. and R.B. Wallace. 1991. Allelespecific polymerase chain reaction. Methods: A Companion to Methods Enzymol. 2:42-48.

14.Wittwer, C.T., K.M. Ririe, R.V. Andrew, D.A. David, R.A. Gundry and U.J. Balis. 1997. The LightCycler ${ }^{\mathrm{TM}}$ : a microvolume multisample fluorimeter with rapid temperature control. BioTechniques 22:176-181.

15.Wu, D.Y., L. Ugozzoli, B.J. Pal and R.B. Wallace. 1989. Allele-specific enzymatic amplification of $\beta$-globin genomic DNA for diagnosis of sickle cell anemia. Proc. Natl. Acad. Sci. USA 86:2757-2760.
The authors would like to thank members of the MRC Human Genetics Unit Cystic Fibrosis Group for their assistance and advice with this work-particularly $\mathrm{Dr}$. Christopher Boyd for manuscript proofreading. This work was supported by the Medical Research Council (UK) and a collaborative research agreement with Boehringer Mannheim. Address correspondence to Dr. Peter H. Thorpe, Molecular Genetics Section, MRC Human Genetics Unit, Crewe Road, Edinburg, EH4 2XU, Scotland, UK. Internet; peter.thorpe@hgu.mrc.ac.uk

Received 17 December 1998; accepted 25 March 1999.

Peter H. Thorpe and David J. Porteous MRC Human Genetics Unit Edinburgh, Scotland, UK 